\title{
The Indian Summer Monsoon Intraseasonal Oscillations in CFSv2 Forecasts: Biases and Importance of Improving Air-Sea Interaction Processes ${ }^{\mathscr{O}}$
}

\author{
YUANLONG LI \\ Key Laboratory of Ocean Circulation and Waves, Institute of Oceanology, Chinese Academy of Sciences, \\ Qingdao, China, and Department of Atmospheric and Oceanic Sciences, University of Colorado Boulder, \\ Boulder, Colorado, and Function Laboratory for Ocean Dynamics and Climate, Qingdao National \\ Laboratory for Marine Science and Technology, Qingdao, China \\ WEIQING HAN \\ Department of Atmospheric and Oceanic Sciences, University of Colorado Boulder, Boulder, Colorado \\ WANQIU WANG \\ Climate Prediction Center, NOAA/NWS/NCEP, College Park, Maryland \\ LEI ZHANG \\ Department of Atmospheric and Oceanic Sciences, University of Colorado Boulder, Boulder, Colorado
}

\section{RAVICHANDRAN}

National Center for Antarctic and Ocean Research, Vasco de Gama, India

(Manuscript received 19 September 2017, in final form 18 March 2018)

\begin{abstract}
Northward-propagating Indian summer monsoon intraseasonal oscillations (MISOs) are a major origin of the active-break spells of the monsoon rainfall. Forecast results for 28 active and 27 break spells from the National Centers for Environmental Prediction (NCEP) Climate Forecast System, version 2 (CFSv2), during 1999-2010 are analyzed. CFSv2 forecasts are able to represent the propagation of MISOs from the equator to central India, showing improvements in many aspects compared to its previous version. Systematic biases for MISOs, however, still exist, exhibiting apparently weaker amplitude and slower northward propagation compared to observations. The eastern Arabian Sea (EAS)-western Bay of Bengal (WBB) region (EASWBB region; $12^{\circ}-20^{\circ} \mathrm{N}, 65^{\circ}-85^{\circ} \mathrm{E}$ ) is found to be critical for the MISO prediction. In that region, the forecast and observed MISO trajectories begin to bifurcate from each other, and forecast errors grow rapidly. Further diagnosis reveals that local air-sea interaction in that region is severely underrepresented in CFSv2. Sea surface temperature (SST) response to surface heat flux forcing and convection response to SST forcing are both too weak, leading to the underestimated MISO amplitude. The relationship between precipitation and SST in CFSv2 is much more chaotic than in observation. The misrepresentation of air-sea coupling results in longer MISO periods in the EAS-WBB region, manifesting as slower propagation and delayed arrival of MISOs in central India. Refining the air-sea coupling processes is crucial for improving the CFSv2 forecast. This includes taking into account the ocean skin layer, better resolving the diurnal cycle, and improving the ocean model physics.
\end{abstract}

Supplemental information related to this paper is available at the Journals Online website: https://doi.org/10.1175/JCLI-D-170623.s1.

Corresponding author: Yuanlong Li, yuanlong.li@colorado.edu

\section{Introduction}

The Indian summer monsoon (ISM) rainfall exhibits prominent intraseasonal variability, manifesting as fluctuations between the active spell with good rainfall and the break spell with little rainfall over India 
(Goswami and Ajaya Mohan 2001; Webster et al. 2002; Rajeevan et al. 2010). The active-break spells are largely caused by the northward-propagating, 30-60-day monsoon intraseasonal oscillations (MISOs) from the equator of the Indian Ocean (e.g., Sikka and Gadgil 1980; Yasunari 1980). Since the active-break spells directly affect agriculture and the food supply of South Asia (Gadgil and Rupa Kumar 2006), understanding and predicting the MISOs are one of the central tasks of climate research community. Yet realistic simulation and accurate prediction of the MISOs are still challenging for the present generation of climate models. Major deficiencies exist in the simulated amplitude, spatial structure, propagation, and precipitation-sea surface temperature (SST) relationship of MISOs (e.g., Seo et al. 2007; Lin et al. 2008; Sabeerali et al. 2013; Sperber et al. 2013; Goswami et al. 2014), and it is difficult to extend useful prediction skill beyond about 2 weeks (e.g., Wang et al. 2005; Fu et al. 2007, 2008, 2011; Wang et al. 2009; Rai and Krishnamurthy 2011; Abhilash et al. 2014).

Many mechanisms have been put forward to explain the northward-propagating MISOs, involving both atmospheric internal instability (e.g., Wang and Xie 1997; Lawrence and Webster 2002; Jiang et al. 2004) and airsea coupling processes (e.g., Kemball-Cook and Wang 2001; Fu et al. 2002, 2003; Joseph and Sabin 2008). The importance of the ocean in the MISO dynamics has been increasingly recognized (e.g., Webster et al. 1998; Vecchi and Harrison 2002; Roxy and Tanimoto 2007, 2012). Particularly, large-scale SST anomalies in the eastern Arabian Sea (EAS) and Bay of Bengal play a vital role in modulating the MISO convection (KemballCook and Wang 2001; Vecchi and Harrison 2002; Joseph and Sabin 2008; Li et al. 2016, 2017b). Observational studies revealed that SST shows prominent covariance with the MISO and possesses a quadrature phase relationship with the intraseasonal convection/precipitation anomaly (e.g., Sengupta et al. 2001; Duvel and Vialard 2007; Roxy et al. 2013). Prior to the active spell, largescale SST warming up to $1.0 \mathrm{~K}$ is observed, favoring the growth and organization of atmospheric convection (Sengupta et al. 2001; Kemball-Cook and Wang 2001; Joseph and Sabin 2008). Subsequently, SST cooling induced by the convection impels the transition of the MISO from active to break phase (e.g., Vecchi and Harrison 2002; Li et al. 2017b). Modeling studies demonstrate that climate models with an actively coupled ocean component are able to more realistically simulate the MISO characteristics than stand-alone atmosphere models (e.g., Fu et al. 2002; Fu and Wang 2004; Seo et al. 2007; Sharmila et al. 2013) and achieve significantly extended prediction skills (e.g., Waliser et al. 2001; Fu et al. 2007, 2008; Wang et al. 2009).
The National Centers for Environmental Prediction (NCEP) Climate Forecast System, version 2 (CFSv2), model (S. Saha et al. 2014) has been used for the seasonal and extended-range operational forecasts of ISM rainfall since 2011 in the Indian Institute of Tropical Meteorology (IITM). Recent studies have conducted extensive evaluation and diagnosis for CFSv2 simulations and forecasts (e.g., Rai and Krishnamurthy 2011; Kim et al. 2012; Jiang et al. 2013; S. K. Saha et al. 2014b). They showed that CFSv2 has achieved a good fidelity in simulating the climatological ISM rainfall distribution and its interannual variability (e.g., Roxy et al. 2013; Bombardi et al. 2015; Narapusetty et al. 2016; Ramu et al. 2016; Abhik et al. 2017) and obtained satisfying improvements in simulating the MISO compared to its previous version (CFSv1), showing more realistic spatial structure and propagation behavior (Roxy et al. 2013; Sharmila et al. 2013; Goswami et al. 2014). The prediction of CFSv2 has also been examined by many studies (e.g., Abhilash et al. 2014; Goswami et al. 2015; Sahai et al. 2015; Abhik et al. 2016). Its skill in forecasting the Madden-Julian oscillation (MJO; Madden and Julian 1971) over the global tropics reaches 2-3 weeks (e.g., Fu et al. 2011; Wang et al. 2014). Abhilash et al. (2014) examined the CFSv2 forecast of the MISO and found that useful deterministic forecast of CFSv2 can be achieved with a lead of approximately 10 days, and the maximal positive prediction skill is about 17 days. They also revealed that the forecasts for break spells are more skillful than those for active spells.

Despite these advances, systematic biases are detected in CFSv2. In addition to the well-known dry bias over central India (Goswami et al. 2014; Narapusetty et al. 2016; Ramu et al. 2016), CFSv2-simulated MISOs show slower northward propagation (Sharmila et al. 2013; Goswami et al. 2014) and biased precipitationSST relationship (Roxy et al. 2013), which greatly hinder the accurate prediction of ISM rainfall. Reducing the model biases requires accurate identification of the problematic model processes, and this study aims to advance our knowledge in this aspect. Specifically, we first evaluate the CFSv2's performance in forecasting active-break spells of ISM rainfall and associated MISO events, by identifying the biases for 28 active and 27 break spells in CFSv2 forecasts during 1999-2010. Then, we investigate the causes for the biases, by diagnosing intraseasonal air-sea coupling processes in CFSv2. A linear local air-sea interaction model is employed to examine the key processes misrepresented in the model. The rest of the paper is organized as follows. Section 2 introduces observational and reanalysis datasets and CFSv2 forecasts. Section 3 describes the selection of the MISO events and their observed characteristics. Section 4 
examines the CFSv2 forecasts and identifies the biased processes in air-sea interaction. Section 5 reaches conclusions and proposes possible means for improving CFSv2 forecasts.

\section{Model and data}

\section{a. CFSv2 reforecasts}

CFSv2 is a fully coupled atmosphere-ocean-land-sea ice model. Its atmospheric component is the Global Forecast System (GFS), which adopts a spectral triangular truncation of 126 waves $(\mathrm{T} 126 ; \sim 100 \mathrm{~km})$ and a finite differencing in the vertical direction with 64 sigma-pressure hybrid layers. Its ocean component is the Geophysical Fluid Dynamics Laboratory (GFDL) Modular Ocean Model, version 4.0d (MOM4; Griffies et al. 2003), with a zonal resolution of $0.5^{\circ}$ and a meridional resolution changing gradually from $0.25^{\circ}$ between $10^{\circ} \mathrm{S}$ and $10^{\circ} \mathrm{N}$ to $0.5^{\circ}$ poleward of $30^{\circ} \mathrm{S}$ and $30^{\circ} \mathrm{N}$ and 40 vertical layers. The top-layer thickness is $10 \mathrm{~m}$, and therefore SST represents the bulk temperature of 0-10 m. In the present study, we analyze the CFSv2 45-day "high priority" reforecasts initialized daily from January 1999 to March 2011. The latest version of the NCEP climate reanalysis product, the Climate Forecast System Reanalysis (CFSR; Saha et al. 2010), is used as the initial condition. For each initial date, forecasts were performed every $6 \mathrm{~h}$ from $0000,0600,1200$, and 1800 UTC, forming a daily four-member ensemble. Daily mean fields of ensemble precipitation, SST, surface shortwave and longwave radiations, latent and sensible heat fluxes, and ocean mixed layer depth (MLD) are used for our analysis.

\section{b. Data}

CFSv2 forecasts are validated against observational and reanalysis data during 1999-2011. The observed precipitation is the daily $1^{\circ} \times 1^{\circ}$ precipitation estimates of the Global Precipitation Climatology Project (GPCP), version 1.2 (Huffman et al. 2001), produced by optimally merging satellite measurements and precipitation gauge analyses. For SST, we use the Tropical Rainfall Measuring Mission (TRMM) Microwave Imager (TMI) V7 product (Wentz et al. 2000), which provides $0.25^{\circ} \times 0.25^{\circ}, 3$-day running mean, daily SST fields based on satellite microwave measurements.

We also analyze precipitation, SST, and surface heat fluxes of CFSR. As a state-of-the-art climate reanalysis product, CFSR uses 6-hourly forecast results of CFSv2 as the first guess. Satellite and in situ ocean observations are assimilated into CFSR using a three-dimensional variational data assimilation (3DVAR) scheme. Temperature of the top layer (also $10 \mathrm{~m}$ in thickness) is strongly nudged to the daily Optimum Interpolation SST (OISST) product based on AVHRR and AMSR satellite measurements and in situ temperature data (Reynolds et al. 2007). Compared to previous reanalysis products, CFSR can much better represent the climatology and variability of the tropical atmosphere and ocean (Xue et al. 2011; Wang et al. 2011). Most importantly, the representation of intraseasonal precipitation variability associated with MISOs and MJOs are greatly improved (e.g., Wang et al. 2012; Li et al. 2016), which contributes to the improved MISO forecast of CFSv2.

\section{Selection of MISO events}

A widely used method of isolating intraseasonal variability is applying a bandpass filter to the original anomaly time series, but this method cannot be used for the 45-day forecast results because of the end-point effect of the filter. Here we utilize a method similar to that of Wang et al. (2014), which removes the variations on other time scales and uses the remnant to represent intraseasonal signals. For both observational and reanalysis data of 1999-2010, three steps are applied for a given variable $V: 1)$ remove the daily climatology $V_{\mathrm{DC}}$ (seasonal cycle) to obtain the raw anomaly $A_{1}$ (i.e., $A_{1}=$ $\left.V-V_{\mathrm{DC}}\right) ; 2$ ) obtain the low-frequency anomaly $A_{\mathrm{LP}}$ by applying a 100-day Lanczos low-pass filter to $A_{1}$ and remove $A_{\mathrm{LP}}$ from $A_{1}$ (i.e., $A_{2}=A_{1}-A_{\mathrm{LP}}$ ); and 3 ) the intraseasonal anomaly (ISA) is obtained by applying a 15-day Lanczos low-pass filter to $A_{2}$, which damps synoptic signals. Averaged over the central India region $\left(18^{\circ}-26^{\circ} \mathrm{N}, 73^{\circ}-85^{\circ} \mathrm{E}\right)$, precipitation ISA is highly consistent with the 20-90-day bandpass-filtered precipitation anomaly, showing a correlation of $r=0.89$. In section 4 , we will show that this method, with some modifications, is also suitable for CFSv2 45-day forecasts. Here we do not take into account the 10-20-day mode of the MISO (e.g., Chatterjee and Goswami 2004) so as to focus solely on the northward-propagating 30 60-day mode.

The standard deviation (STD) map of precipitation ISA during June-September (JJAS) represents the spatial distribution of MISO-related intraseasonal variations (Fig. 1a). The central India region, used for the definition of active-break spells (e.g., Rajeevan et al. 2010; Abhilash et al. 2014; Narapusetty et al. 2016), is featured by STDs of 6-9 $\mathrm{mm}^{-1 a y}{ }^{-1}$ and flanked by two lobes of stronger variability $\left(>10 \mathrm{~mm} \mathrm{day}^{-1}\right)$. One is a slanted narrow belt covering the western Ghats and coastal area of the EAS, while the other is located in the northern Bay of Bengal. The EAS-western Bay of Bengal (WBB) region (EAS-WBB region) also shows pronounced intraseasonal variability of SST (Fig. 1b). A 
(a) GPCP precipitaion ISA

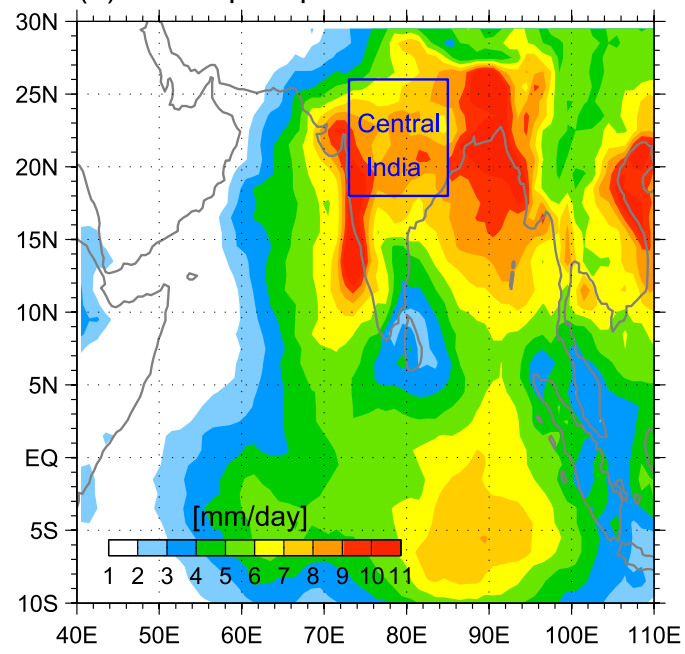

(b) TMI SST ISA

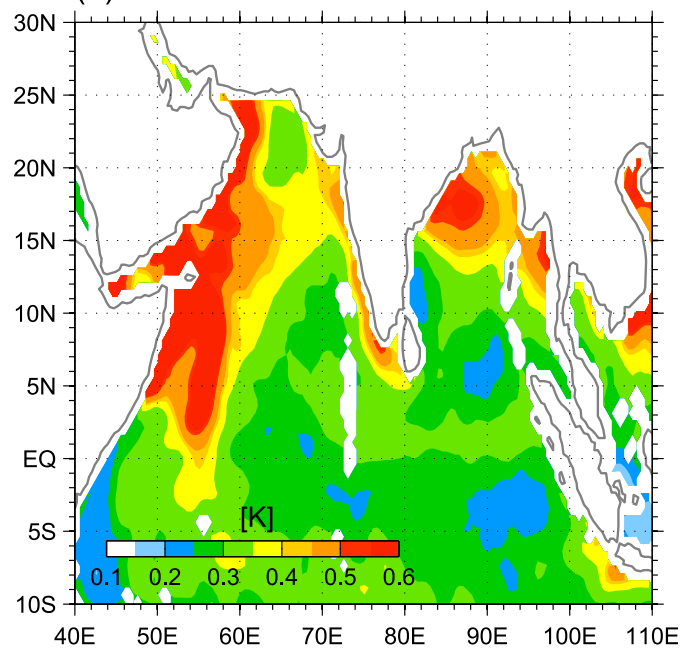

FIG. 1. STD maps of (a) precipitation ISA and (b) SST ISA for JJAS during 1999-2010 based on respectively GPCP and TMI data. The blue rectangle in (a) denotes the central India region $\left(18^{\circ}-26^{\circ} \mathrm{N}, 73^{\circ}-85^{\circ} \mathrm{E}\right)$.

local STD maximum $(>0.5 \mathrm{~K})$ stands out in the northern part of the WBB, while STDs $>0.4 \mathrm{~K}$ are seen in the coastal areas of the EAS. Note that these SST and precipitation anomalies are much stronger than those near the equator. This distribution indicates that air-sea coupling in the EAS-WBB region may act to enhance MISOs before they reach central India and thereby affect the active-break spells (Vecchi and Harrison 2002; Wang et al. 2009; Sharmila et al. 2013).

The selection of MISO events is based upon the precipitation ISA of central India (Fig. 2), with the active and break spells defined as the maxima and minima exceeding one STD value, respectively. Since CFSR is the initial condition of CFSv2 forecast, it is used for the selection of MISO events instead of GPCP. In fact, CFSR precipitation is generally consistent with GPCP in central India, except for several events. For the 28 active spells and 27 break spells identified in CFSR during the summers of 1999-2010 (a period determined by the availability of CFSv2 45-day reforecasts), 50 can also be identified in GPCP with a time lag of $0-2$ days. There are 10 GPCP events not captured by CFSR. For these events, CFSv2 forecasts are not able to correctly reproduce owing to the large errors in the initial condition, and therefore are not analyzed here. Using CFSR for event selection, we ignore the errors contained in the initial condition and focus on the problems of CFSv2 forecast model.

The composite ISA maps of the selected events show northward propagation of the MISO from the equator to central India (Fig. 3). On the zero day of the active spell the wet condition of central India is accompanied with stronger wet signatures in the northeastern Arabian Sea and the Bengal of Bengal. These wet anomalies can be traced back to the EAS-WBB region at $-5,-10$, and -15 days and farther back to the equator at -15 and -20 days. Noteworthy are the warm SST anomalies of $>0.2 \mathrm{~K}$ in the EAS-WBB at -10 and -15 days, which precede the wet anomalies at -5 and -10 days. They are suggested to be important in enhancing the convection of the MISO through destabilizing the lower atmosphere (e.g., Sengupta et al. 2001; Kemball-Cook and Wang 2001; Joseph and Sabin 2008; Roxy et al. 2013; Li et al. 2016). The wet conditions are tailed by cold SST anomalies to the south, which are believed to be important for termination of the active condition and transition to the break condition (e.g., Vecchi and Harrison 2002; Li et al. 2017b). The composite maps of the break condition are roughly the same as those of the active except with the opposite sign (Fig. 3b). One interesting feature worthwhile mentioning is that the break condition has its maximum signature exactly over central India on day 0, and anomalies are weaker in either the EAS or the bay, a pattern in contrast to that of the active condition. One can also see that the central India region is mainly affected by the MISO signatures within $65^{\circ}-85^{\circ} \mathrm{E}$. Although strong variations are seen east of $85^{\circ} \mathrm{E}$ in the bay, these signals are subsequent to those over central India. Our following analysis is hence focused on the $65^{\circ}-85^{\circ} \mathrm{E}$ band.

\section{MISO events in CFSv2 forecasts}

\section{a. Evaluation of forecasts}

Since $V_{\mathrm{DC}}$ and $V_{\mathrm{LP}}$ cannot be computed with the 45-day CFSv2 forecast results, we extract ISA using a modified method. First, $V_{\mathrm{DC}}$ and $V_{\mathrm{LP}}$ of CFSR are 

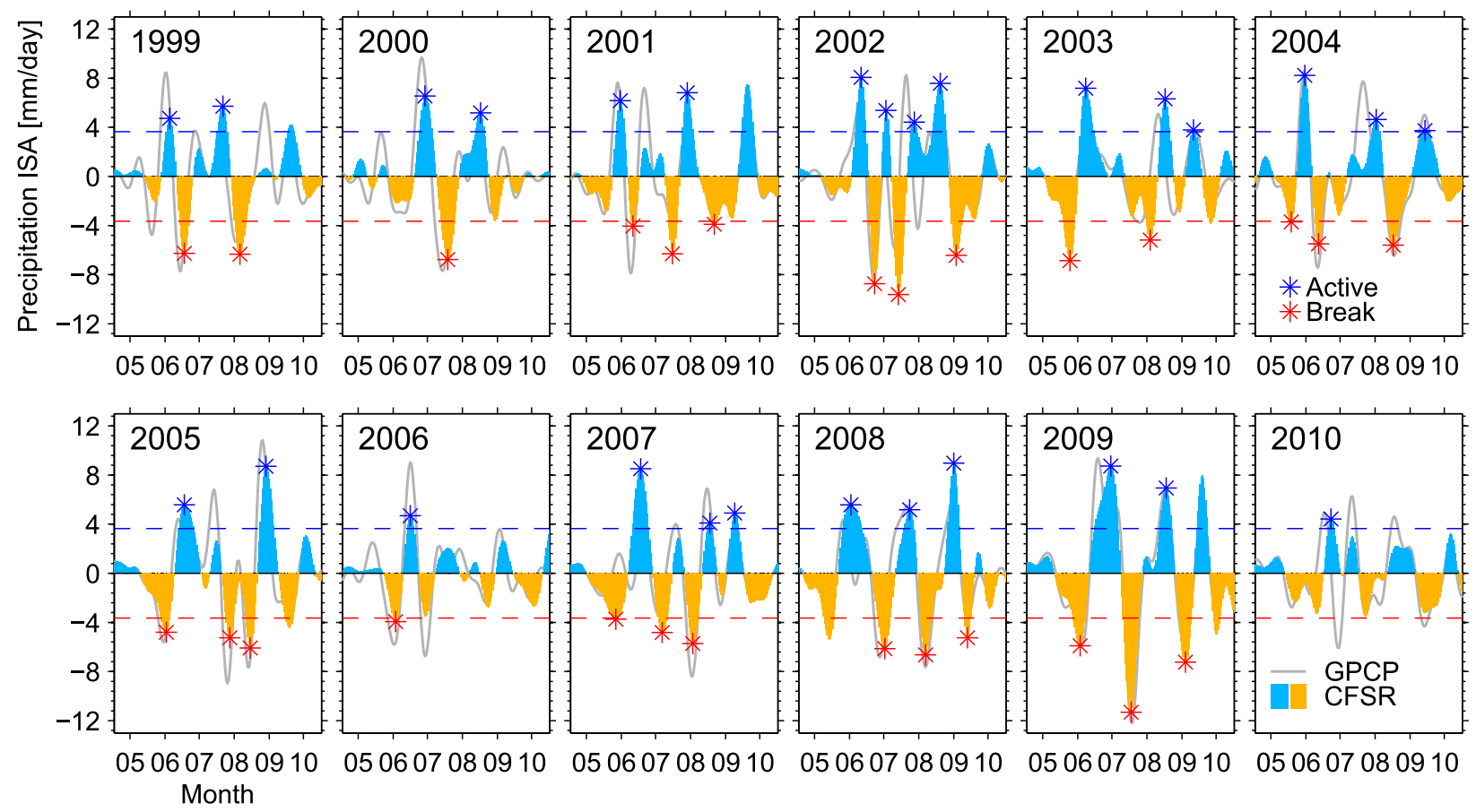

FIG. 2. Time series of precipitation ISA averaged over central India from CFSR for 1999-2010. Active and break spells (blue and red asterisks) are identified as the extrema exceeding the STD range (dashed lines). GPCP precipitation ISA is also shown for comparison (gray line).

removed from CFSv2 forecasts to obtain the forecast $A_{2}$. Then, for each 45-day time series of forecasts, CFSR $A_{2}$ before the initiation date is placed before the forecast $A_{2}$, forming a synthesized $A_{2}$ time series consisting of CFSR data and CFSv2 forecast before and after the initiation date, respectively. We further perform a 15-day low-pass filtering for the synthesized $A_{2}$ to obtain the raw ISA. Employing CFSR $A_{2}$ avoids the end-point effect of the filter at the beginning of forecast. The raw ISA, however, contains the model bias of CFSv2 in simulating the ISM mean state, which greatly contaminates the MISO signal. This bias can be approximately estimated by averaging the mean active-spell forecast $($ mean of 448 streams $=28$ events $\times 4$ initiations $\times 4$ members) and the mean break-spell forecast (mean of 432 streams $=27$ events $\times 4$ initiations $\times 4$ members). Fidelity of the methodology is suggested by the fact that for all the four initiations $(-5,-10,-15$, or -20 days $)$ the averages of active-spell forecast and break-spell forecast are approximately the same (Fig. 4a). By removing this bias from raw ISA, the "true" forecast ISA is obtained (Fig. 4b). One can see that the forecast active and break spells are evidently weaker than observation, and the forecasts with longer leads tend to achieve weaker precipitation ISAs in central India. While Figs. $4 \mathrm{a}$ and $4 \mathrm{~b}$ show the composite results, individual MISO events are displayed in Fig. S1 of the supplemental material. The pattern of model bias in the monsoon region $\left(65^{\circ}-85^{\circ} \mathrm{E}\right)$ is also of interest. CFSv2 has a wet bias in the equatorial region and a dry bias over India (Fig. 4c), as identified in CFSv2 simulation (Goswami et al. 2014; Narapusetty et al. 2016; Ramu et al. 2016), whereas in SST there is a cold bias of approximately $1 \mathrm{~K}$ near the equator and a warm bias of approximately $0.4 \mathrm{~K}$ in the north (Fig. 4d). Given the nonlinearity of the monsoon system, it is expected that these biases in the ocean/atmosphere background state may affect the modeled MISOs.

GPCP and CFSR agree reasonably well in the composite Hovmöller maps (Figs. 5a and 5b, respectively). The active spell manifests as a track of positive ISA moving northward with time, and the total travel time from the equator to $25^{\circ} \mathrm{N}$ is around 16 days. In the north Indian Ocean, the observed ISA is greatly strengthened, from $2 \mathrm{~mm} \mathrm{day}^{-1}$ at $10^{\circ} \mathrm{N}$ to $6 \mathrm{~mm} \mathrm{day}^{-1}$ at $20^{\circ} \mathrm{N}$. CFSR shows stronger wet anomalies over central India than GPCP. This is simply because the events are selected based on CFSR data. Larger discrepancies are seen in SST between CFSR and satellite observation. The SST cooling following the active spell in CFSR is weaker than in TMI data by approximately $0.1 \mathrm{~K}$, and the reasons have been discussed in Li et al. (2016). The satellite microwave instrument measures skin temperature of the ocean, which has significantly stronger variability than 
(a) Active

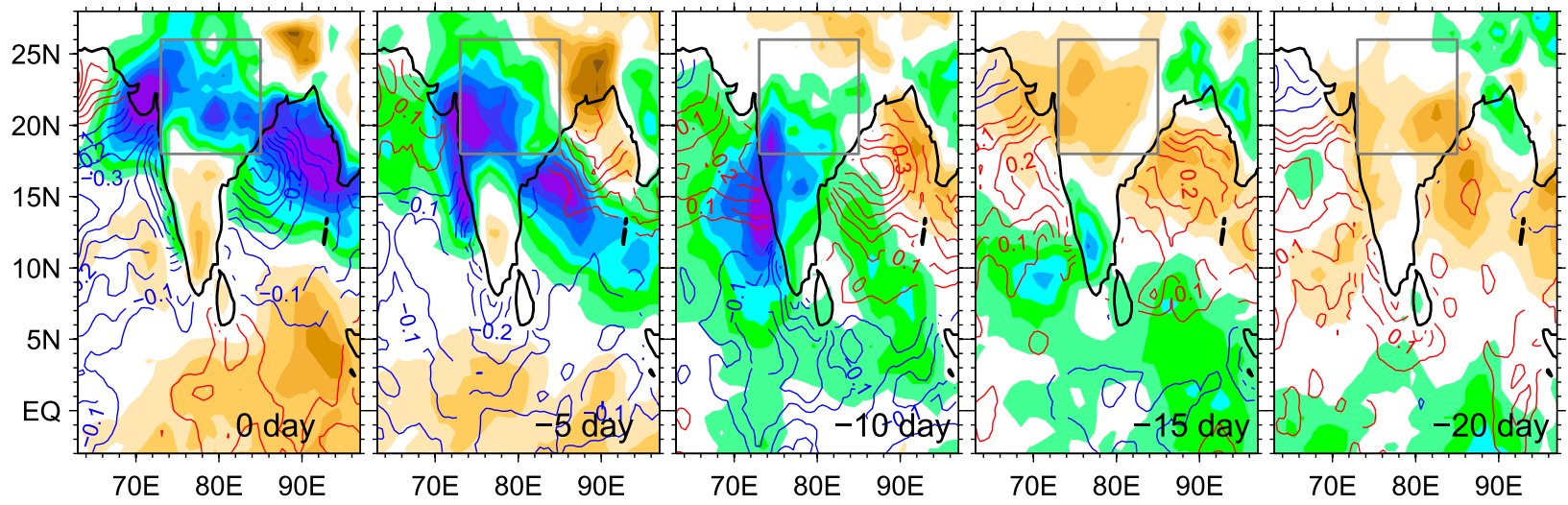

(b) Break

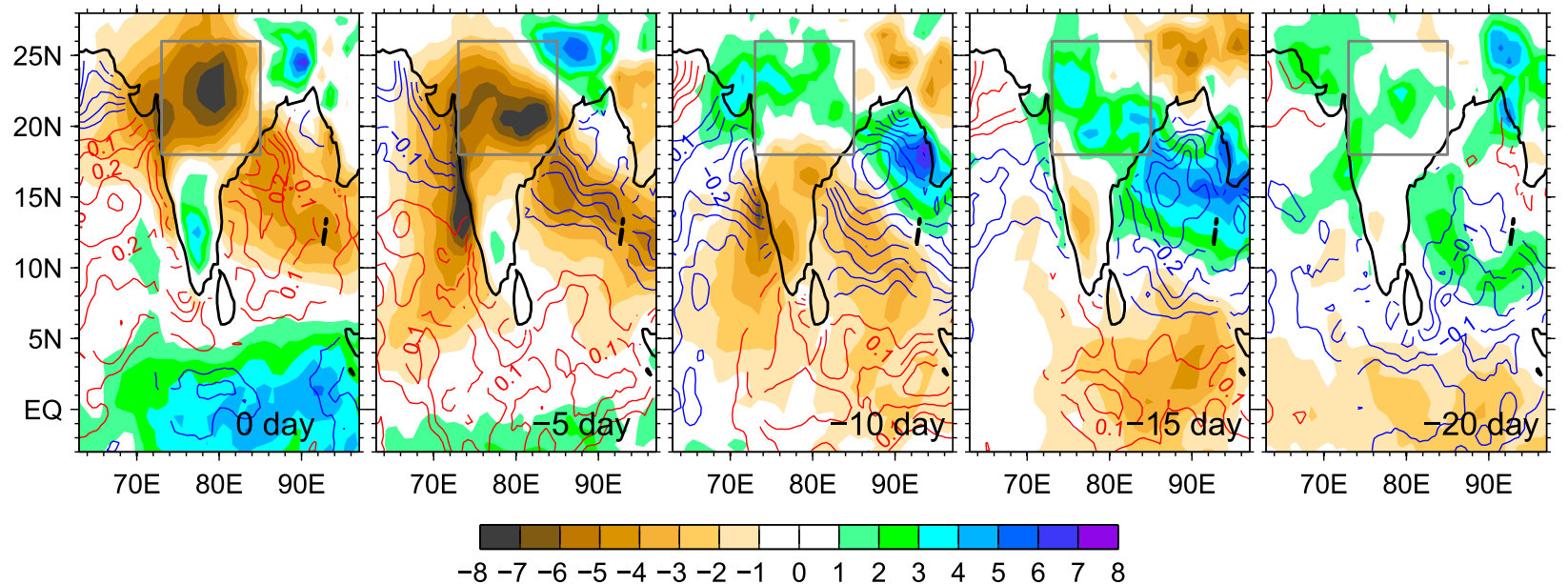

FIG. 3. Composite maps of precipitation ISA (color shading; $\mathrm{mm} \mathrm{day}^{-1}$ ) and SST ISA (red and blue contours for positive and negative values, respectively; interval is $0.05 \mathrm{~K}$ ) based on GPCP and TMI data, respectively, at (left)-(right) $0,-5,-10,-15$, and -20 days for the (a) active and (b) break spells.

the bulk temperature of $0-10 \mathrm{~m}$ in CFSv2 model; in data assimilation CFSR uses OISST that has been adjusted toward in situ data (Reynolds et al. 2007) and thus also weaker than TMI skin temperature in variability. As we shall see below, the errors in initial condition are much smaller than those of forecast results and are not likely the primary source for them. Hereafter we will use CFSR precipitation and TMI SST as the "observations" for the evaluation of CFSv2 forecasts.

The forecasts of CFSv2 with leads of $5,10,15$, and 20 days are shown in Figs. 5c-f, respectively. The positive ISA can reach north of $20^{\circ} \mathrm{N}$ with magnitudes of approximately $2 \mathrm{~mm} \mathrm{day}^{-1}$ in all forecasts except for that initiated from -20 days. CFSv2 also captures the SST anomalies of the MISO, with SST warming prior to and SST cooling following the active spell. Compared with the forecasts of CFSv1 (Wang et al. 2009), CFSv2 has achieved significant improvements, particularly in propagation behavior. The composite MISO in CFSv2 can reach a higher latitude with significant amplitude and propagates at a larger phase speed (closer to observations). Another advancement is that CFSv2 is now able to reproduce the postconvection break spell (a weaker break spell following the active spell in the composite; occurring between +5 and +15 days in central India), albeit with weaker amplitude and delayed timing. This feature was absent in CFSv1. Composites of the break spell show similar spatial-temporal patterns to those of the active spell with the opposite sign (Fig. S2 in the supplemental material). SST cooling and warming anomalies are seen before and after the break spell, respectively. It is difficult to visually identify the differences between the forecast active and break spells. One difference is that in the forecasts from - 10 days the enhancement of the break condition between $15^{\circ}$ and $20^{\circ} \mathrm{N}$ is captured (Fig. S2d), whereas the counterpart feature is absent in Fig. 5d. In both active- and break-spell forecasts, there are southward propagation 

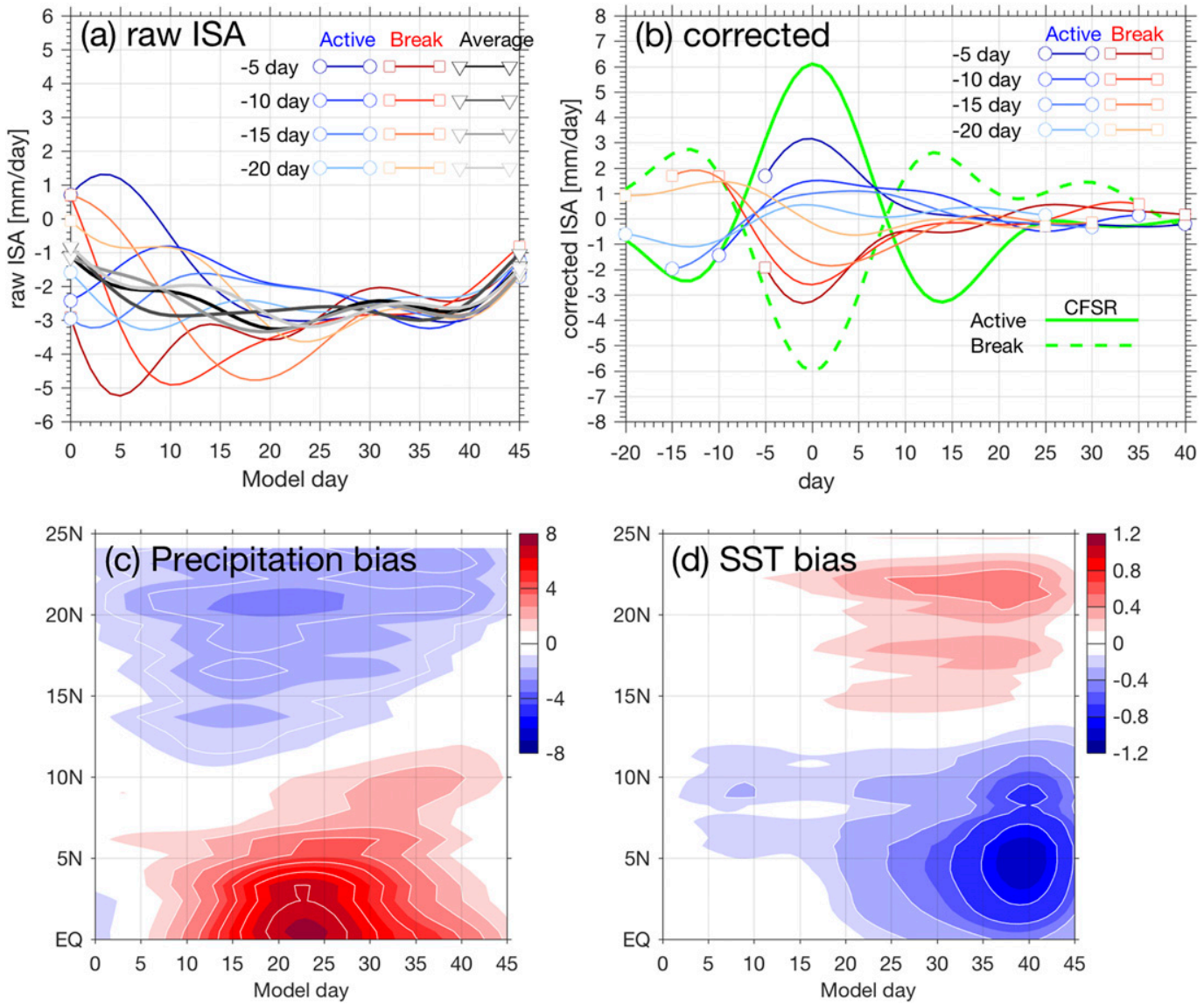

FIG. 4. (a) Composite raw precipitation ISA of CFSv2 forecasts in central India as a function of the model day. Forecasts starting from $-5,-10,-15$, and -20 days are plotted separately. Forecasts for active and break spells are blue and red lines, respectively, and their averages are gray lines. (b) Corrected (mean removed) composite precipitation ISA from CFSv2 forecasts in central India as a function of time lag are compared with the CFSR composites (green; solid for the active spell and dashed for the break spell). Time-latitude plots of the CFSv2 forecast bias in (c) precipitation $\left(\mathrm{mm} \mathrm{day}^{-1}\right)$ and (d) SST (K) averaged between $65^{\circ}$ and $85^{\circ} \mathrm{E}$.

signals from about $5^{\circ} \mathrm{N}$ to $5^{\circ} \mathrm{S}$ that are, however, absent in observations.

Despite the significant advancements, CFSv2 still shows significant biases. First, as expected, the forecast spells are evidently weaker than in observations. Second, although improved, the arrival time of the MISO in central India is still delayed, reflecting a slower northward propagation. This is clearly seen in the forecasts at $-10,-15$, and -20 days. This issue will be further quantified below. Third, the MISO anomalies tend to persist for a longer duration, showing lower-frequency oscillations than in observations, which are discerned by both precipitation and SST. Fourth, the SST cooling (warming) following the active (break) spell is weaker, and the phase relationship between SST and precipitation still shows discrepancies from observations. Take the active spell as an example. The response of SST to convection is too slow, and the phase lag between the active spell and its resultant SST cooling is too long ( $\sim 18$ days if measured at $15^{\circ} \mathrm{N}$ for the -15 -day forecast, as compared to $\sim 11$ days in observations or CFSR). All these biases have already been seen in CFSv1 (Wang et al. 2009), and in fact some of them have already been quantitatively reduced in CFSv2.

To evaluate the prediction skill of the active-break spells, correlation and root-mean-square error (e.g., Lin et al. 2008; Wang et al. 2014) are computed for the precipitation ISA over central India (Fig. 6). With leads of 5-15 days, forecasts of the break events achieve evidently higher correlations and smaller errors than the active events. With a lead of 20 days, both active and break spells cannot be predicted with useful skills. The active-spell forecasts show a dramatic drop of correlation when the lead time increases from 5 to 10 days (Fig. 6a), corresponding to the abrupt growth of forecast error (Fig. 6b). From 10 to 15 days, there is a slight rise in 
(a) GPCP \& TMI

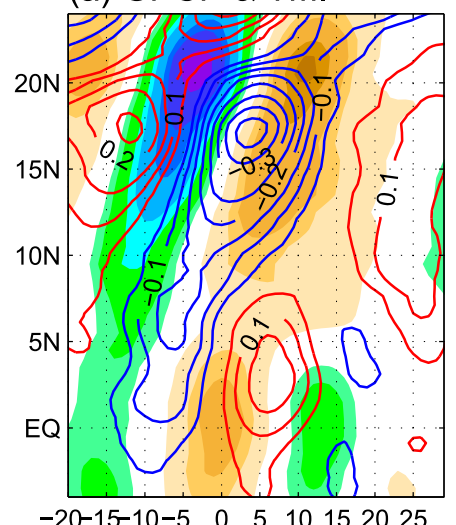

(b) CFSR

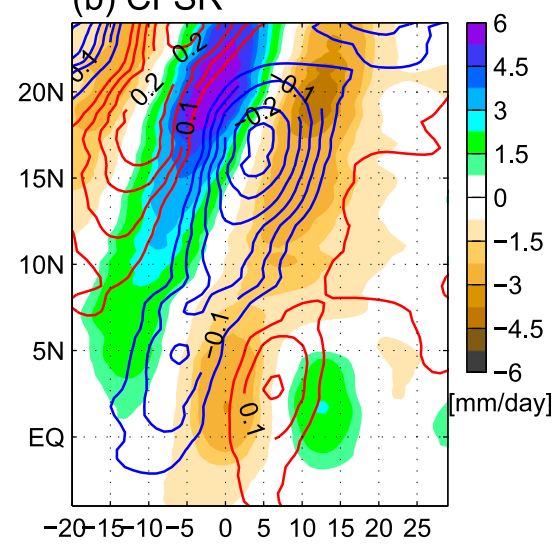

(c) CFSv2 ( -5 day)

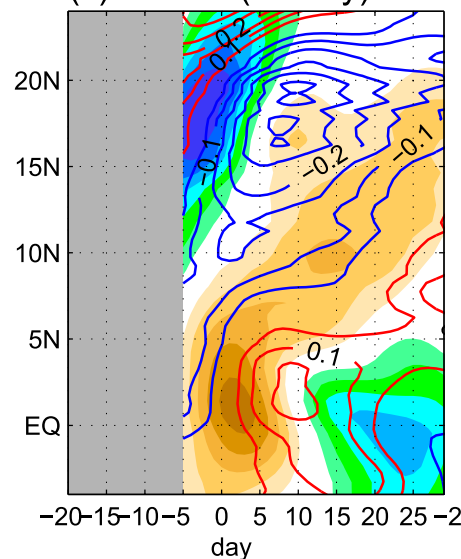

(d) CFSv2 (-10 day)

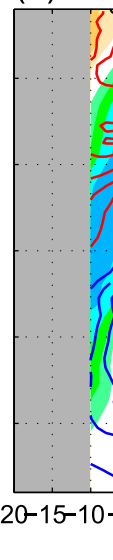

(e) CFSv2 ( -15 day)

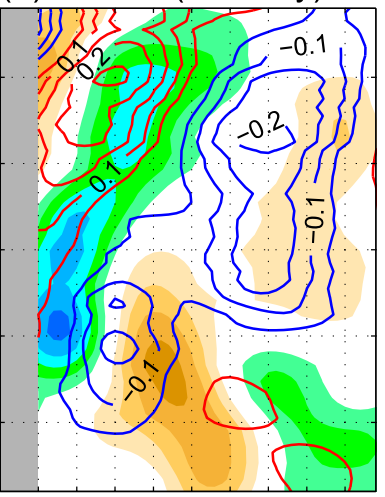

(f) CFSv2 (-20 day)

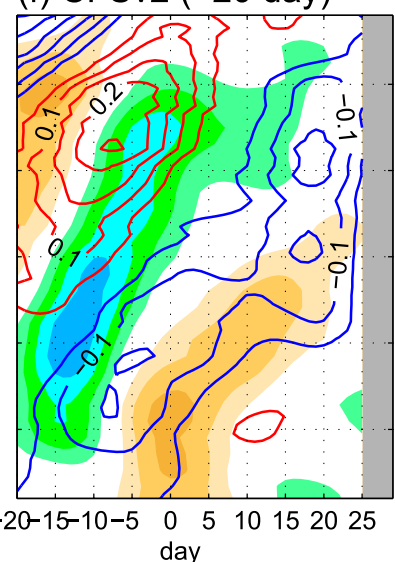

FIG. 5. Time-latitude plots of precipitation ISA (color shading) and SST ISA (red and blue contours for positive and negative values, respectively; interval is $0.05 \mathrm{~K}$ ) averaged between $65^{\circ}$ and $85^{\circ} \mathrm{E}$ for the active spell composite derived from (a) GPCP and TMI, (b) CFSR, and (c)-(f) CFSv2 forecasts initiated from $-5,-10,-15$, and -20 days, respectively.

correlation, which does not necessarily indicate a significant increase of prediction skill, given that the forecast error is still rising. In comparison, the break-spell forecasts show smoother and slower error growth. Here the prediction skills are assessed only for the 28 active and 27 break events. A more robust estimation involving the entire ISM rainfall time series was provided by Abhilash et al. (2014), which gave similar results as ours except with prevailingly higher skill values. Strong MISO events, particularly the enhanced convection during the active phase, are the major difficulty for the ISM rainfall prediction.

A close inspection of the error fields (forecast minus observations) provides clues for identifying model problems (Fig. 7). Forecasts with different lead times show quite similar error patterns, except for greater magnitudes in longer-range forecasts, implying systematic biases of the model. This well-structured pattern shows a dry bias before and a wet bias after the activespell peak (day 0), and the opposite bias structure is seen in the break-spell forecasts. This error evolution again suggests the delayed arrival and weaker amplitude of the MISO in model. At the beginning of the forecast, the error was quite small in the equatorial region. But when the MISO reaches north of about $12^{\circ} \mathrm{N}$, the errors grow rapidly and finally reach as large as the observed composite anomalies $\left(4-6 \mathrm{~mm} \mathrm{day}^{-1}\right)$. Also in this region, large SST errors emerge and show a quadrature relationship with precipitation error. The coexistence and tight relationship of SST and precipitation errors indicate that air-sea interaction in the north Indian Ocean is important for the MISO and its prediction, and its misrepresentation in CFSv2 may be a major error source of the forecasts. This is in line with the finding of previous modeling studies (e.g., Fu et al. 2007, 2008; Wang et al. 2009; Sharmila et al. 2013), which have demonstrated that without air-sea coupling, MISOs cannot propagate farther than about $14^{\circ} \mathrm{N}$.

The slower propagation of the MISO is a major shortcoming in CFSv2 forecast, which deserves 

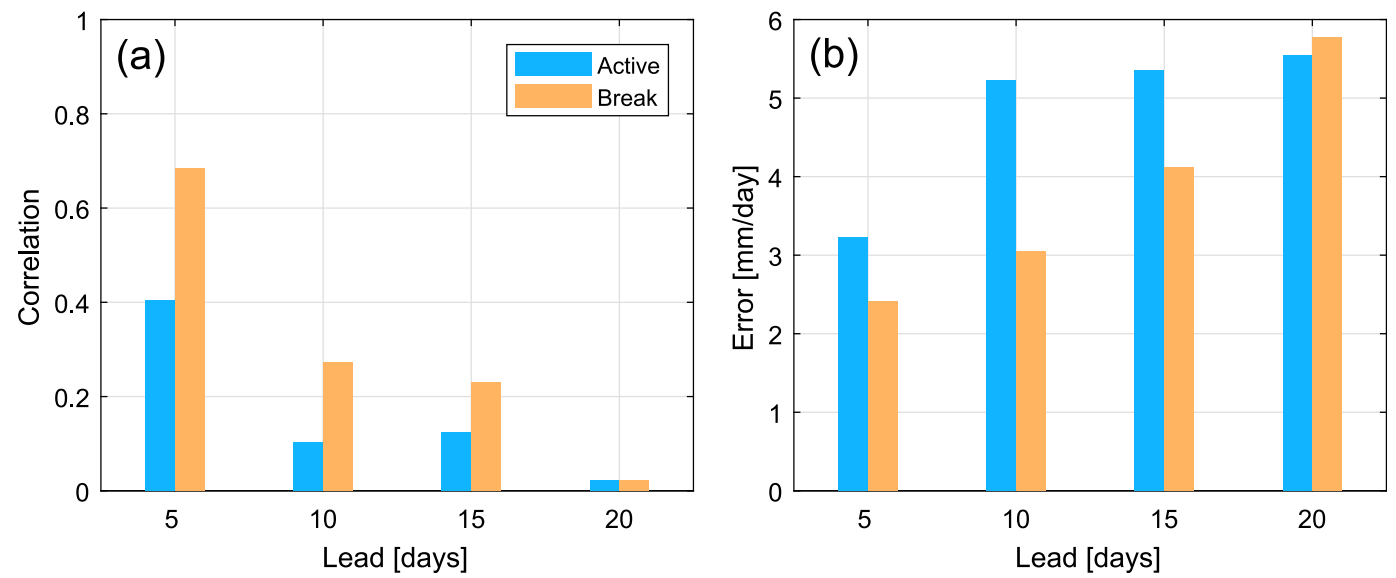

FIG. 6. (a) Correlation and (b) root-mean-square error of precipitation ISA in central India between CFSv2 forecasts and CFSR for the 28 active and 27 break spells, computed separately for forecasts from $-5,-10,-15$, and -20 days.

further inspection. Given that the forecasts from -5 and -10 days do not capture the entire anomaly track from the equator to central India and the forecast from -20 days shows little skill, hereafter we mainly analyze the forecast from -15 days. To quantify the propagation of the active and break spells, here we use the passage time $t_{P}(y)$ of the spell center at different latitudes:

$$
t_{P}(y)=\frac{\int_{T_{\min }}^{T_{\max }} P(y, t) t d t}{\int_{T_{\min }}^{T_{\max }} P(y, t) d t} .
$$

In the above $P(y, t)$ is the precipitation ISA averaged between $65^{\circ}$ and $85^{\circ} \mathrm{E}$, and $t$ is the lag time. Here $T_{\max }=$ $(y-5) / c_{1}$ and $T_{\min }=(y-55) / c_{2}$ are the integration limits shown as gray dashed lines in Fig. 8 , where $c_{1}=1^{\circ}$ lat day $^{-1}$ and $c_{2}=3^{\circ}$ lat day ${ }^{-1}$, and 5 and 55 are the intercepts. Note that only positive (negative) $P(y, t)$ values are included in the integral for the active (break) spell events, and the unit of $t$ is in day here. The variables $T_{\max }$ and $T_{\min }$ are defined to include as much as possible the positive (negative) $P(y, t)$ associated with the active (break) spells, and slightly altering their parameters does not significantly affect the results. The observed and forecast $t_{P}(y)$ for active and break spells are compared in Fig. 8, where the individual events and the composite are plotted as dots and thick curves, respectively. For either active or break spell, the forecast composite MISO is delayed in arriving at $24^{\circ} \mathrm{N}$ by around 5 days as compared to observations. It is interesting that the propagation of MISOs from the equator to $12^{\circ} \mathrm{N}$ shows good agreement with observations. It is at about $12^{\circ} \mathrm{N}$ that the forecasts and observations begin to bifurcate from each other, and their discrepancy enlarges with latitude. Therefore, the region north of $12^{\circ} \mathrm{N}$ is likely most problematic in CFSv2 forecast. The air-sea interaction in this region requires in-depth diagnosis.

\section{b. Air-sea interaction processes}

The above analysis presented in section 4 a suggests the rapid growth of correlated precipitation and SST errors in the EAS-WBB region $\left(12^{\circ}-20^{\circ} \mathrm{N}, 65^{\circ}-85^{\circ} \mathrm{E}\right)$, and also in this region the forecast MISO trajectories bifurcate from the observed ones. It is possible that the air-sea interaction in CFSv2 fails to maintain the MISO as in observations, leading to the weakening and delayed arrival of the forecast MISOs. In this subsection, we try to explain the forecast errors with the misrepresented air-sea interaction in the EAS-WBB region in CFSv2. A simplified theoretical framework is employed to depict the air-sea coupled intraseasonal oscillation and diagnose its model representation in CFSv2.

Observational and modeling studies have demonstrated that in this region MISOs induce intraseasonal SST variability primarily through surface heat fluxes (e.g., Sengupta et al. 2001; Duncan and Han 2009; Vialard et al. 2012; Li et al. 2016, 2017b). Therefore, we focus on analyzing the relationships among surface heat fluxes, SST, and precipitation to examine the air-sea interaction processes. Figure 9 shows the composite evolutions of precipitation, SST, surface net heat flux $Q_{\text {net }}$, along with heat flux components in the EAS-WBB region. In observations (Figs. 9a,c), precipitation (blue shading) reaches its maximum (minimum) at $-4(-3)$ days in this region, characterizing the peak of the active (break) phase of the composite MISO. Correspondingly, $Q_{\text {net }}$ (red line) shows a minimum (maximum) during the 
(a) -5 day

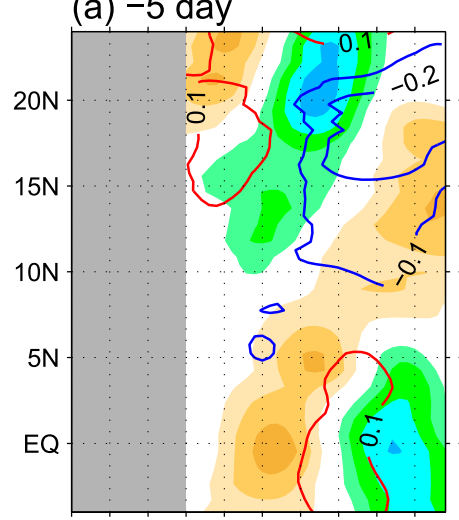

(b) -10 day

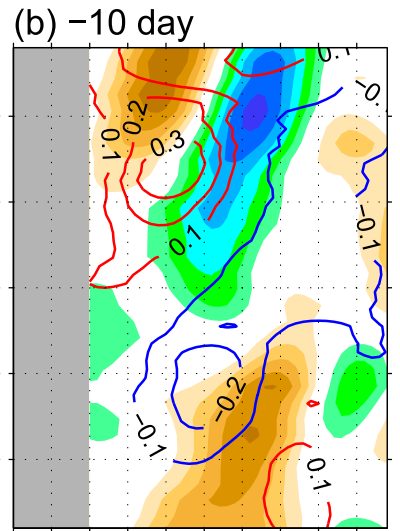

(c) -15 day (d) -20 day

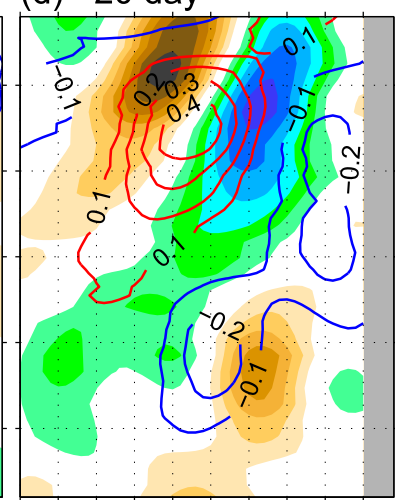

-20-15-10-5 $0 \quad 5 \quad 10152025-20-15-10-5 \quad 0 \quad 5 \quad 10152025-20-15-10-5 \quad 0 \quad 5 \quad 10152025-20-15-10-5 \quad 0 \quad 5 \quad 10 \quad 152025$

(e) -5 day

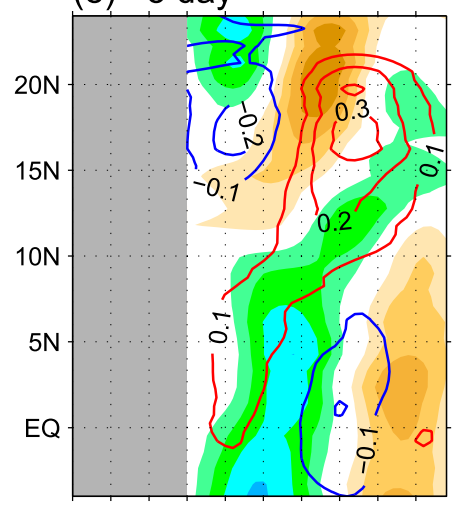

$\begin{array}{rr}-20-15-10-5 & 0 \\ & \\ & \text { day }\end{array}$ (f) -10 day

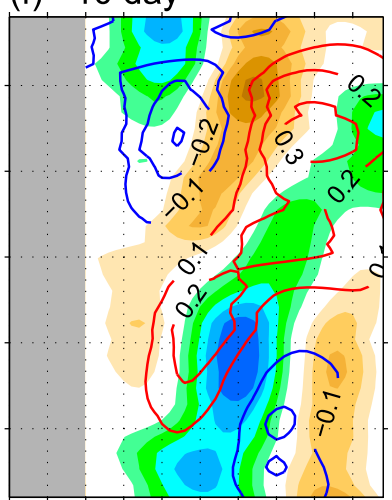

(g) -15 day

(h) -20 day
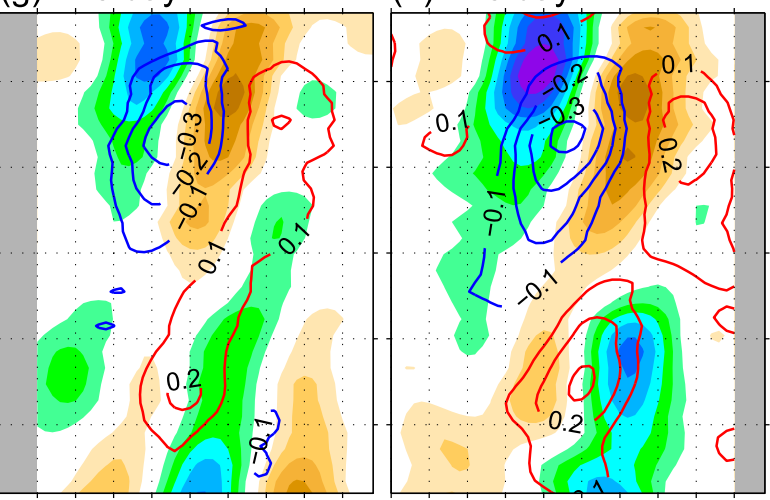

day

FIG. 7. Errors of precipitation ISA (color shading) and SST ISA (red and blue contours; interval is $0.1 \mathrm{~K}$ ) of CFSv2-forecast composite active spell relative to CFSR precipitation and TMI SST. Variables are averaged between $65^{\circ}$ and $85^{\circ} \mathrm{E}$ and plotted separately for the forecasts from (a) -5 , (b) -10 , (c) -15 , and (d) -20 days. (e)-(h) As in (a)-(d), but for the composite break spell.

active (break) phase. The phase of $Q_{\text {net }}$ is almost out of phase with precipitation. Among the three components of $Q_{\text {net }}$, shortwave radiation (SWR; orange line) and turbulent heat flux $Q_{T}$ (latent plus sensible heat fluxes; green line) both have major contributions to $Q_{\text {net }}$, while longwave radiation (LWR; blue line) has a negative contribution to $Q_{\text {net }}$. These relationships are in line with our conventional understanding that the active phase of the MISO (characterized by strong deep convection and rainfall) involves increased cloudiness, which blocks SWR toward sea surface, and enhanced monsoonal winds increase the ocean's $Q_{T}$ loss to the atmosphere (Sengupta et al. 2001; Vecchi and Harrison 2002; Duvel and Vialard 2007; Roxy and Tanimoto 2007, 2012). The opposite situation occurs in the break phase.

SST anomalies (black line) show well-organized quadrature relationships with precipitation and $Q_{\text {net }}$. As the primary driver of SST variability, $Q_{\text {net }}$ maxima and minima correspond to the largest SST warming and cooling rates (at roughly SST anomaly $=0$ ), respectively; when $Q_{\text {net }}=0$, SST reaches an extreme value $(\partial \mathrm{SST} / \partial t=0)$. Existing studies have shown that during MISO events, intraseasonal tendency of mixed layer temperature $T_{M}$ (a good proxy for SST) can be largely explained by $Q_{\text {net }}$ absorbed by the mixed layer [e.g., $\partial T_{M} / \partial t=Q_{\text {net }} / c_{p} \rho_{0} H_{M}$, where $c_{p}$ and $\rho_{0}$ are the specific heat capacity and density of seawater, respectivley, and $H_{M}$ is the MLD (e.g., Shinoda et al. 1998; Roxy et al. 2013; Li et al. 2014, 2016)]. This is because in the mixed layer budget of the MISO, ocean advection and subsurface entrainment terms are one order smaller than surface heat flux forcing term (e.g., Li et al. 2016, 2017b).

A similar relationship is seen between SST and precipitation. The SST anomaly is proportional to the tendency of precipitation. This relationship was first put forward by Lindzen and Nigam (1987), who demonstrated that warm (cool) SST anomaly leads to moisture convergence (divergence) and thus enhanced 

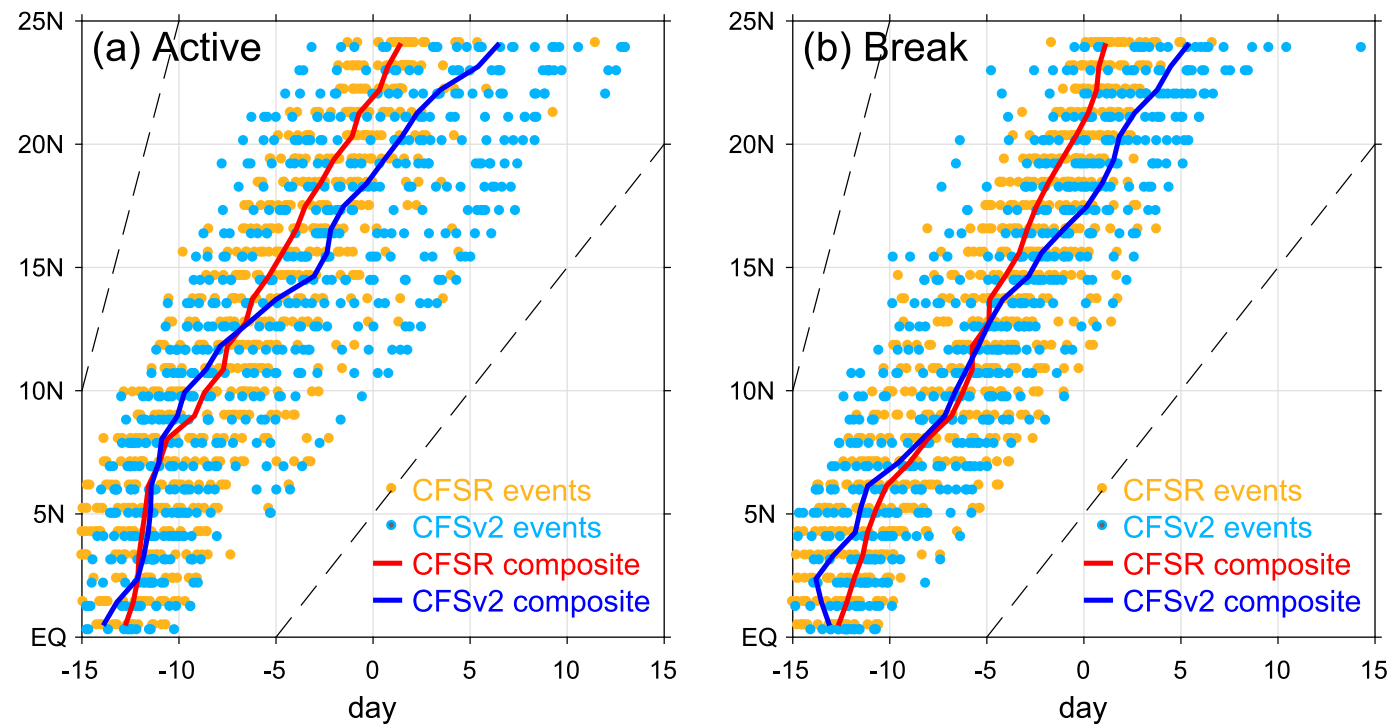

FIG. 8. Passage time $t_{P}(y)$ of the MISO center as a function of latitude for (a) the active spell and (b) the break spell, showing the propagation of the MISO derived from CFSv2 forecasts initiated from -15 days and CFSR. Individual events and their composite are drawn as dots and a thick curve, respectively. The two dashed thin lines denote the integration limits for the computation of $t_{P}(y)$. See the text for details.

(weakened) precipitation. Later research found close relationships between the SST anomaly, moisture convergence, lower-atmospheric instability, and precipitation in observational data (e.g., Roxy and Tanimoto 2007, 2012; Zhang et al. 2018, manuscript submitted to J. Climate), and many observational studies have reported a delayed response of atmospheric convection to SST forcing during MISO events (e.g., Sengupta et al. 2001; Vecchi and Harrison 2002; Li et al. 2017b). Zhang et al. (2018, manuscript submitted to J. Climate) depicted the relationship between SST and precipitation as $\partial P / \partial t \propto \mathrm{SST}$, where both precipitation $P$ and SST are ISAs.

Checking the CFSv2 forecasts from -15 days (Figs. 9b,d) suggests that the above relationships between $P, Q_{\text {net }}$, and SST in observations are also valid in CFSv2. However, the forecast MISO anomalies are weaker in amplitude and longer in oscillatory period than observations. For instance, the forecast active and break spells have only half of the observed magnitudes and evidently prolonged durations ( $\sim 24$ vs $\sim 13$ days). These deficiencies are likely related to quantitative biases in the coupling processes. Taking the active spell forecast as an example, the positive $Q_{\text {net }}$ before -15 days is not weaker than in observations (in fact it is stronger), but its SST response (warming) at -10 days is weaker than observations by approximately $20 \%$, suggesting an ocean less sensitive to $Q_{\text {net }}$ forcing. The $P$ response to the about $20 \%$ weaker SST warming is weaker than in observations by approximately $50 \%$ at -4 days, indicative of weaker response of atmospheric convection to
SST forcing. Weaker convection is accompanied with a smaller negative $Q_{\text {net }}$ anomaly, which further results in slower decay of the SST warming from -15 to +15 days, during which the low sensitivity of the ocean to $Q_{\text {net }}$ forcing again decelerates the decay. The prolonged SST warming leads further to a prolonged active spell. The termination of the active spell is delayed by about 10 days in CFSv2. It is therefore likely that the underrepresented air-sea coupling processes, such as lower sensitivity of ocean response to $Q_{\text {net }}$, are responsible for not only the weaker amplitude but also the prolonged period of the forecast MISO.

Quantitative estimates are required to support the above analysis and to identify the degree to which CFSv2 has underrepresented the air-sea coupling. We employ a theoretical framework of local air-sea interaction that mathematically represents the observed intraseasonal relationships of $P$, SST, and $Q_{\text {net }}$, which is a simplified version of the local air-sea interaction model proposed by Zhang et al. (2018, manuscript submitted to J. Climate),

$$
\begin{aligned}
Q_{\text {net }} & =k_{1} P, \\
\frac{\partial \mathrm{SST}}{\partial t} & =k_{2} Q_{\mathrm{net}}, \\
\frac{\partial P}{\partial t} & =k_{3} \mathrm{SST},
\end{aligned}
$$

where $k_{1}$ quantifies the negative correlation between $P$ and $Q_{\text {net }}, k_{2}$ measures the efficiency of the SST response 

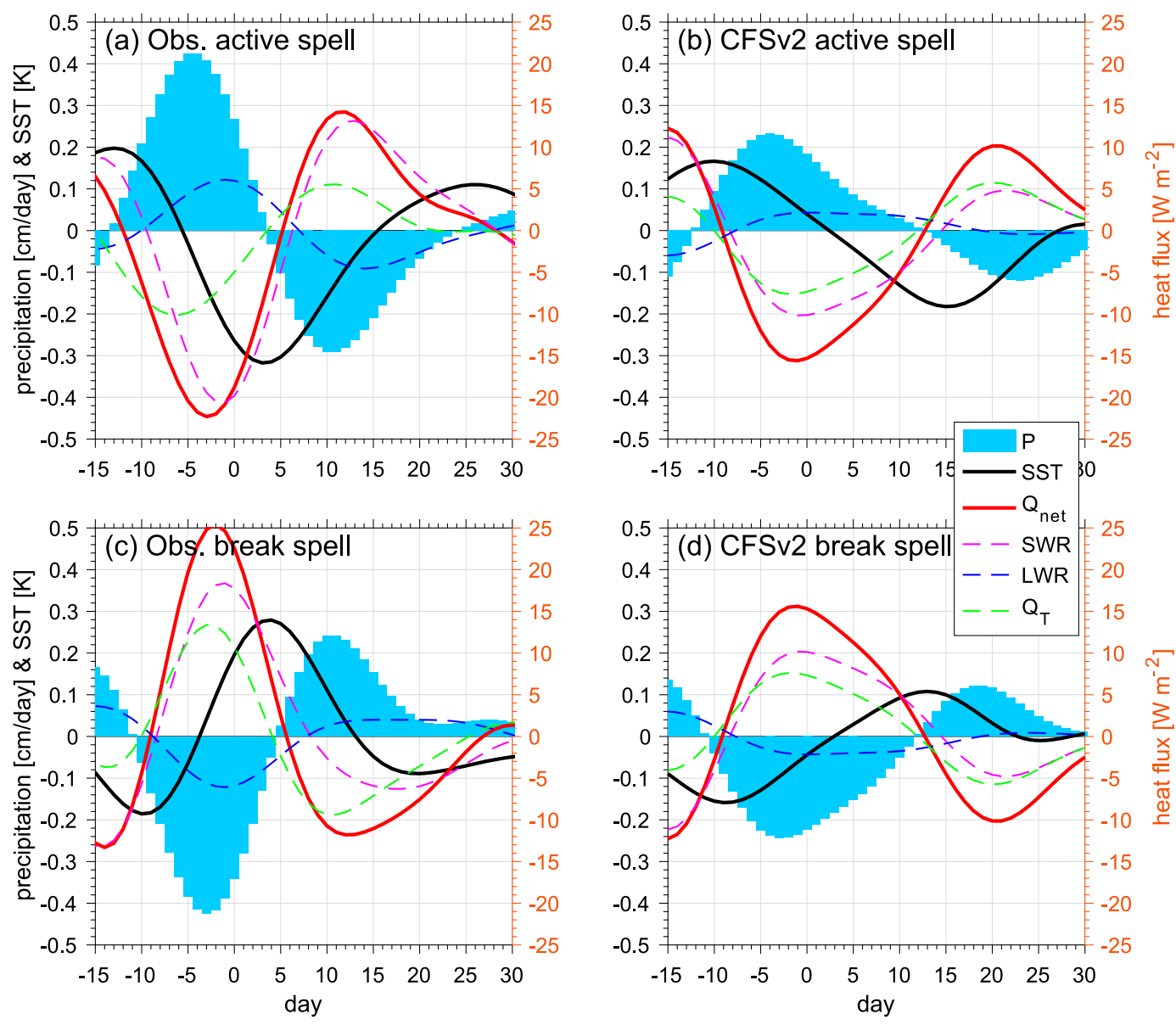

FIG. 9. Composite ISA time series of precipitation, SST, $Q_{\text {net }}$, SWR, LWR, and $Q_{T}$ averaged over the EAS-WBB region $\left(12^{\circ}-20^{\circ} \mathrm{N}, 65^{\circ}-85^{\circ} \mathrm{E}\right)$ for the active spell derived from (a) observations (SST from TMI data, and other variables from CFSR) and (b) CFSv2 forecasts initiated from -15 days. (c),(d) As in (a),(b), but for the break spell. Note that the peak precipitation anomalies occur between -5 and -3 days for active and dry spells as shown in the figure because the MISO events are chosen based on the precipitation in the central India region, which is north of the EAS-WBB region.

to $Q_{\text {net }}$, and $k_{3}$ represents the sensitivity of $P$ to SST forcing. Here $k_{1}, k_{2}$, and $k_{3}$ can be estimated for observations and forecast results through a linear least squares fitting (Fig. 10). The tight out-of-phase relationship between $P$ and $Q_{\text {net }}$ is well captured by CFSv2 (Fig. 10b), as compared with observations (Fig. 10a). Their correlation coefficient is -0.82 and -0.84 in observations and CFSv2, respectively. Here $k_{1}$ is $-6.03 \mathrm{~W} \mathrm{~m}^{-2}$ $\left(\mathrm{mm} \mathrm{day}^{-1}\right)^{-1}$ in CFSv2, which is slightly larger in magnitude than that in observation $\left[-5.35 \mathrm{~W} \mathrm{~m}^{-2}\left(\mathrm{~mm} \mathrm{day}^{-1}\right)^{-1}\right]$. It means that for a given $P$ anomaly, CFSv2 tends to overestimate its heat flux forcing on the ocean by approximately $15 \%$. Therefore, $k_{1}$ is not the error source of the weak amplitude and long period of the forecast MISO.

The relationship between $\partial \mathrm{SST} / \partial t$ and $Q_{\text {net }}$ is also tight (Figs. 10c and 10d, respectively), showing high correlations ( 0.83 vs 0.88$)$ and small fitting errors $(0.033$ and $\left.0.017 \mathrm{~K} \mathrm{day}^{-1}\right)$. However, $k_{2}$ is remarkably smaller in CFSv2 $\left[1.2 \times 10^{-3} \mathrm{~K} \mathrm{day}^{-1}\left(\mathrm{~W} \mathrm{~m}^{-2}\right)^{-1}\right]$ than in observations $\left[2.0 \times 10^{-3} \mathrm{~K}\right.$ day $\left.^{-1}\left(\mathrm{~W} \mathrm{~m}^{-2}\right)^{-1}\right]$. The response of SST to heat flux forcing of the MISO is underestimated by about $40 \%$ in CFSv2. This leads to weaker SST anomalies in the forecasts, even if $Q_{\text {net }}$ is slightly overestimated, as has been seen in Fig. 10. The most problematic process in CFSv2 is the response of convection to SST forcing. In observations, $\partial P / \partial t$ and SST show a correlation of 0.74 and a $k_{3}$ of $1.71 \mathrm{~mm} \mathrm{day}^{-2} \mathrm{~K}^{-1}$, whereas in CFSv2 they are degraded to 0.47 and $0.92 \mathrm{~mm} \mathrm{day}^{-2} \mathrm{~K}^{-1}$. The scatter is visibly more disorderly in CFSv2, showing a larger fitting error $\left(0.839\right.$ vs $\left.0.514 \mathrm{~mm} \mathrm{day}^{-2}\right)$. It means that the response of atmospheric convection to SST forcing is not only significantly underestimated (by $\sim 46 \%$ ) but also 
(a) Observation

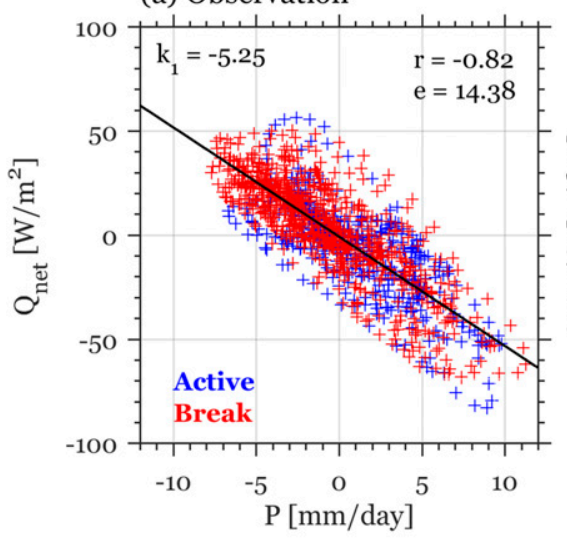

(b) CFSv2

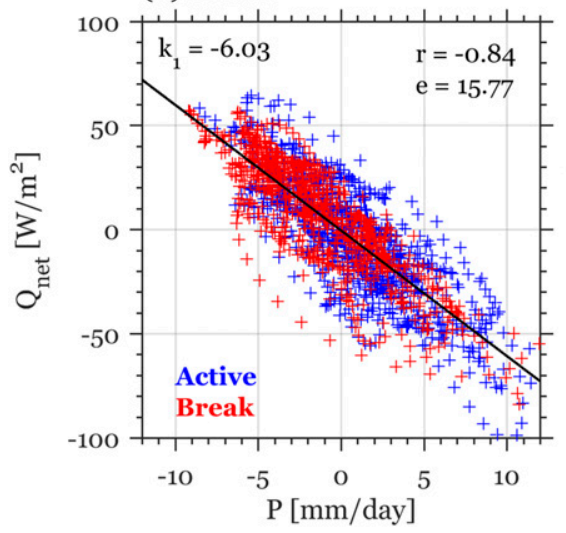

(c) Observation

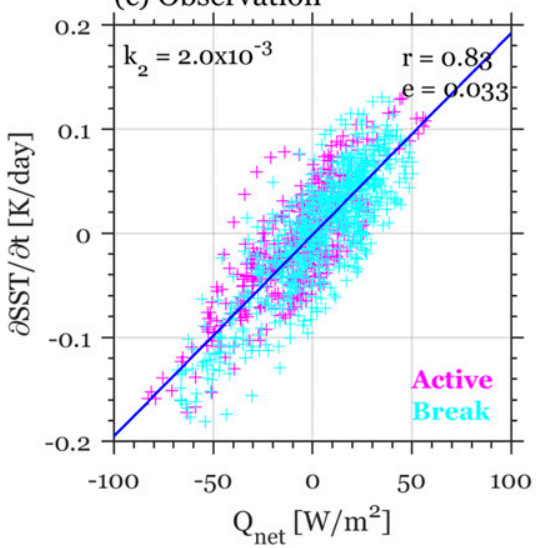

(d) CFSv2

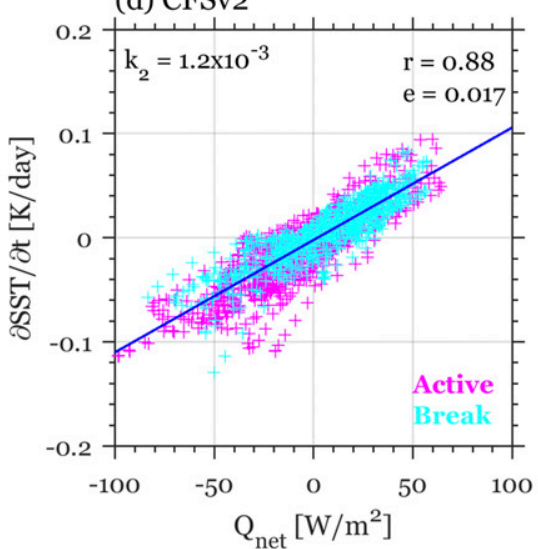

(e) Observation
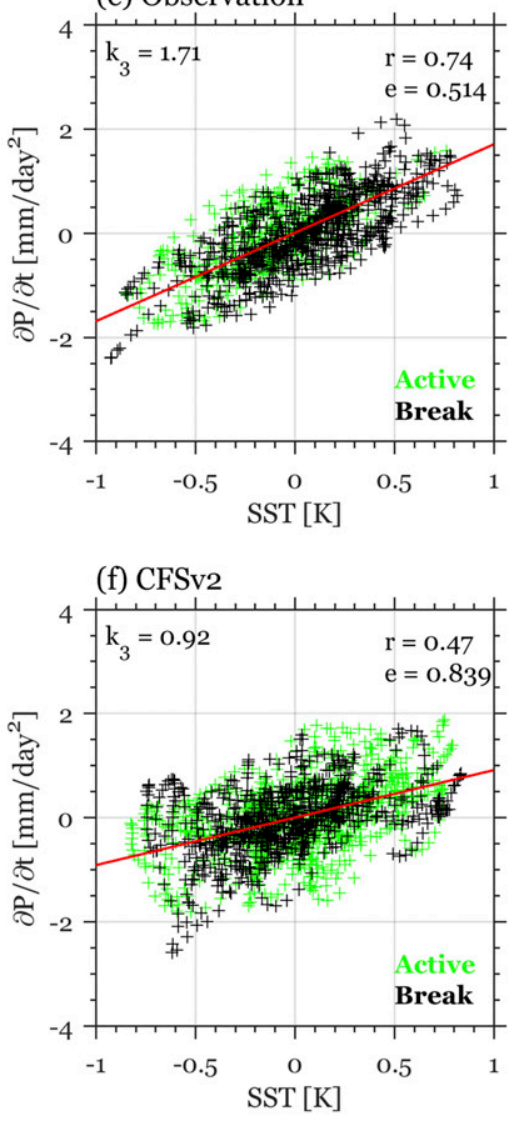

FIG. 10. Scatterplots of precipitation vs $Q_{\text {net }}$ averaged over the EAS-WBB region between -14 and +14 days from (a) observations and (b) CFSv2 forecasts initiated from -15 days. Active events and break events are plotted separately with different colors. The straight line denotes the linear least squares fitting. (c),(d) As in (a),(b), but for $Q_{\text {net }}$ vs $\partial \mathrm{SST} / \partial t$. (e),(f) As in (a),(b), but for SST vs $\partial P / \partial t$. TMI SST, CFSR $Q_{\text {net }}$, and GPCP precipitation are used in (a),(c),(e). All the variables are in the form of ISA.

less organized in CFSv2, which reduces the predictability of the MISO. The smaller $k_{2}$ and $k_{3}$ jointly lead to the significantly weaker amplitude of MISO in CFSv2. We should also note that in our analysis, precipitation and $Q_{\text {net }}$ are averaged over the entire EASWBB region including both ocean and land areas, but SST is averaged only over ocean areas. To assess this influence, we also computed $k_{1}, k_{2}$, and $k_{3}$ only for the ocean areas of EAS and WBB (Figs. S3 and S4 in the supplemental material). It is found that $k_{2}$ is larger in WBB than in EAS [2.4 vs $1.3 \times 10^{-3} \mathrm{~K} \mathrm{day}^{-1}\left(\mathrm{~W} \mathrm{~m}^{-2}\right)^{-1}$ ], but $k_{3}$ is larger in EAS than in WBB (2.12 vs $1.34 \mathrm{~mm} \mathrm{day}^{-2} \mathrm{~K}^{-1}$ ), and similar to the case in Fig. 10, CFSv2 underestimates $k_{2}$ (by $\sim 46 \%$ in EAS and $\sim 50 \%$ in WBB) and $k_{3}$ (by $\sim 47 \%$ in EAS and $\sim 49 \%$ in WBB) in both regions.

In addition to the amplitude, $k_{2}$ and $k_{3}$ also affect the intrinsic period (frequency) of the MISO. The combination of Eqs. (2)-(4) yields a linear oscillatory system:

$$
\frac{\partial^{2} P}{\partial t^{2}}-k_{1} k_{2} k_{3} P=0
$$

and the intrinsic period of the system is

$$
T=\frac{2 \pi}{\sqrt{-k_{1} k_{2} k_{3}}}
$$

It means that smaller $k_{2}$ or $k_{3}$ will enlarge the intrinsic period of the MISO in the EAS-WBB region. The $T$ computed with observed $k_{1}-k_{3}$ is about 47 days, while that based on CFSv2 $k_{1}-k_{3}$ is about 77 days. The two theoretical estimates are evidently longer than those of the composites in Fig. 9 (32 and 64 days). This may be attributed to the fact that this highly simplified theoretical model considers only local air-sea interaction and ignores many processes, such as atmospheric internal dynamics, the nonlinearity of coupling, ocean dynamical and mixing processes, and the remote forcing 

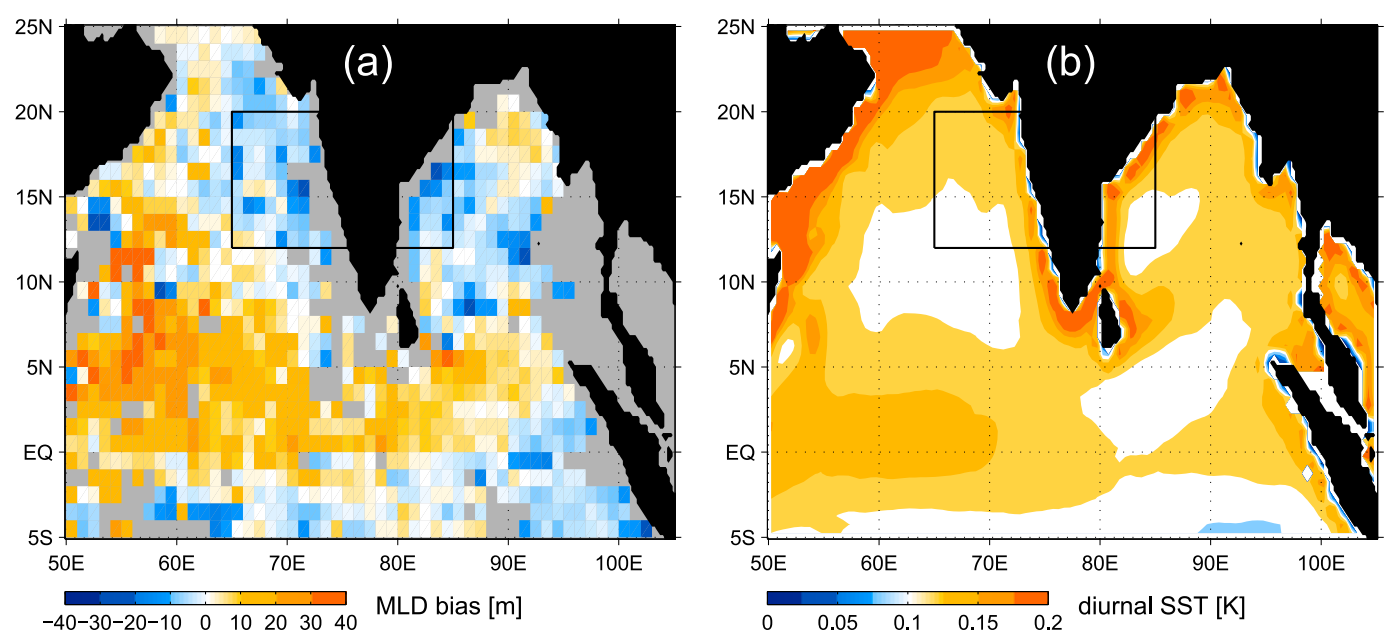

FIG. 11. Climatology of MLD bias and diurnal SST range of CFSv2 forecasts during JJAS 2005-10. (a) The difference in MLD between CFSv2 forecasts and Argo data processed by Li et al. (2017b). (b) Mean diurnal SST range (daytime max minus nighttime min) based on 6-h SST forecasts from CFSv2.

from the equatorial region. Detailed discussion and validation for more complicated versions of the model are provided in Zhang et al. (2018, manuscript submitted to J. Climate). Nevertheless, the diagnosis here has figured out major error sources that can largely explain the biases in CFSv2 forecasts. The longer MISO period (lower frequency) is also a long-standing issue in CFSv2 and CFSv1 simulations and forecasts, which can be easily discerned in previous studies (e.g., Wang et al. 2009; Roxy et al. 2013; Sharmila et al. 2013; Goswami et al. 2014). Importantly, the longer MISO period, with prolonged active and break spells in the EAS-WBB region, directly causes the delayed arrival of MISOs in central India. Here we propose that refining the air-sea coupling processes in CFSv2 may significantly reduce this bias and thereby improve the simulation and prediction of ISM rainfall. To improve the air-sea coupling, it is necessary to examine the model physics that determine the sensitivities of the ocean and atmosphere to each other's forcing $\left(k_{2}\right.$ and $\left.k_{3}\right)$.

Previous studies have pointed out the importance of background ocean MLD in determining the amplitude of intraseasonal SST variability in response to $Q_{\text {net }}$ forcing $\left(k_{2}\right)$ (e.g., Roxy et al. 2013; Li et al. 2014, 2016). The smaller $k_{2}$ in CFSv2 could possibly be induced by a deeper MLD in the model. To test this, we show the difference in climatologic MLD during JJAS between CFSv2 forecast and Argo observations in Fig. 11a, where MLD is computed with a $0.25-\mathrm{kg} \mathrm{m}^{-3}$ potential density criterion (Xue et al. 2011). The observed MLD is computed for individual Argo data profile and objectively mapped into monthly climatology (Li et al. 2017a). Over most of the EAS-WBB region, MLD in CFSv2 forecast is, in fact, shallower than Argo observations by several meters, although there are no sufficient data samplings in the coastal areas. Similar MLD bias distribution was obtained in CFSv2 simulation (Roxy et al. 2013). Therefore, it is likely that the ocean MLD is not an origin of the small $k_{2}$ in CFSv2.

Alternatively, the weaker SST response to $Q_{\text {net }}$ could also be attributed to the absence of the ocean skin layer and insufficient representation of diurnal cycle in the model. Existing studies demonstrated that taking into account the ocean skin layer $(<1 \mathrm{~m})$ and using hourly SWR forcing can strengthen intraseasonal SST variability by up to $20 \%$ in the tropical Indian Ocean rather than using 10-m top layer and daily SWR forcing in ocean models, because of the nonlinearity of the ocean (e.g., Shinoda et al. 1998; Shinoda 2005; Bernie et al. 2007; Mujumdar et al. 2011; Li et al. 2013; Ge et al. 2017). In CFSv2 the mean diurnal SST amplitude (the difference between the daytime SST maximum and nighttime SST minimum) computed within 6-h SST forecasts are only $0.1-0.2 \mathrm{~K}$ in the EAS-WBB region (Fig. 11b), which is much weaker than the $0.3-0.5-\mathrm{K}$ magnitude estimated by observational and modeling studies (e.g., Shenoi et al. 2009; Li et al. 2013). In the present CFSv2 configuration, SST diurnal cycle and its rectification to intraseasonal variability are not sufficiently resolved. In addition, if the realistic diurnal SST anomaly superimposed onto SST ISA, the total SST anomaly could be much stronger than in the present 6-h forecast. Because of the nonlinear relationship between atmospheric deep convection and SST (e.g., Roxy 2014), the response of precipitation to SST forcing may also be improved (i.e., $k_{3}$ ). Therefore, based on the diagnosis provided from an oceanic perspective 
(a) Obs.

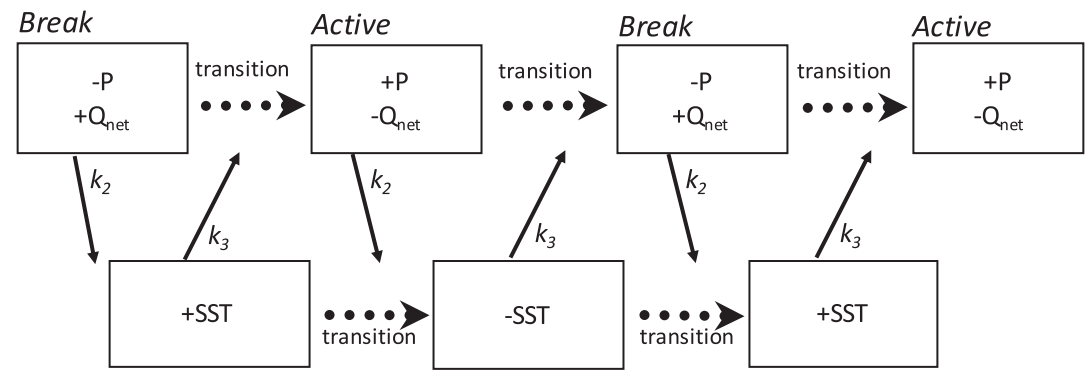

(b) CFSv2

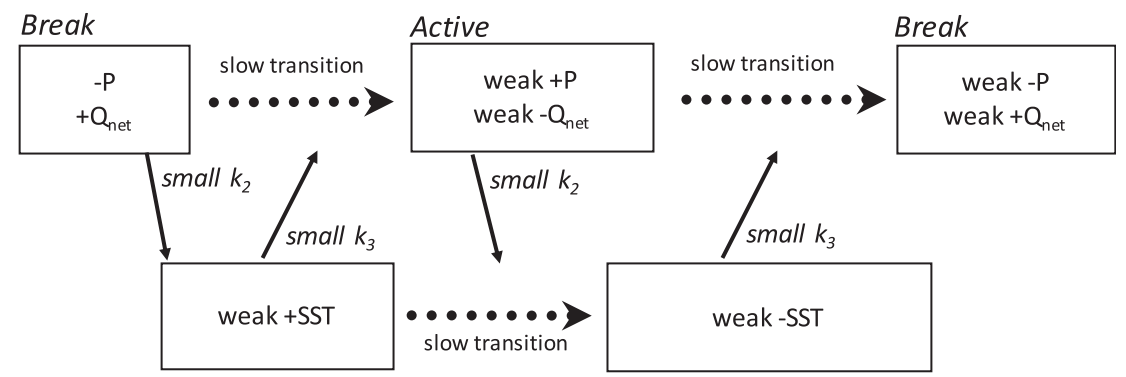

FIG. 12. A schematic figure comparing the air-sea interaction in (a) observations and (b) CFSv2 forecasts.

here, we propose that including/parameterizing the ocean skin-layer temperature and better resolving the diurnal cycle may significantly improve the intraseasonal air-sea interaction in CFSv2 and extend the effective predictability of ISM rainfall.

\section{Conclusions and implications}

Accurate prediction of ISM rainfall on the intraseasonal time scale is of paramount importance for agriculture and other socioeconomic activities of South Asia. In the present study, we evaluate and diagnose the CFSv2 forecasts for 28 active and 27 break events of the ISM rainfall and their associated northwardpropagating MISOs selected during 1999-2010. During the propagation from the equator to central India, MISOs are greatly intensified in the EAS-WBB region, where large-amplitude SST anomalies $(>0.2 \mathrm{~K})$ emerge and likely contribute to the intensification.

The forecasts of CFSv2 initiated from 5, 10, 15, and 20 days before the active and break spells are examined. CFSv2 is capable of representing the northward propagation of MISOs from the equator to central India and their intensification in the north Indian Ocean. Compared to its previous version (CFSv1), CFSv2 has achieved many significant improvements. The forecast MISOs can now reach higher latitudes and propagate at a faster speed. CFSv2 can also well reproduce the strong SST anomalies in the north Indian Ocean and the quadrature relationship between precipitation and SST. There are, however, still systematic biases in CFSv2 forecasts, including 1) weaker amplitudes of rainfall and SST anomalies, 2) slower northward propagation and delayed arrivals of MISOs in central India, and 3) prolonged periods of MISO active-break phases. The prediction skill for these strong active and break events is lower than that for the entire ISM rainfall time series (Abhilash et al. 2014), suggesting difficulties for the models to realistically represent strong MISO events. Prediction skill of break spells is overall higher than that of active spells. The forecast errors in precipitation and SST grow rapidly north of $12^{\circ} \mathrm{N}$. The forecast MISO shows realistic behaviors from the equator to around $12^{\circ} \mathrm{N}$; but north of $12^{\circ} \mathrm{N}$ the forecast and observed MISOs begin to diverge, with the forecast MISO propagating evidently slower than in observations and arriving at $24^{\circ} \mathrm{N}$ later by about 5 days.

A process-oriented diagnosis is conducted to evaluate the air-sea interaction processes in the EAS-WBB region. A theoretical framework depicting the local intraseasonal air-sea interaction [Eqs. (2)-(4)] is employed, in which $k_{2}$ measures the SST response to $Q_{\text {net }}$ forcing, and $k_{3}$ quantifies the precipitation response to SST forcing (Fig. 12a). It is found that both $k_{2}$ and $k_{3}$ are 
significantly smaller in CFSv2 than in observations (by $40 \%$ and $46 \%$, respectively), suggesting that SST response to $Q_{\text {net }}$ and precipitation response to SST are much less sensitive in CFSv2. In addition, the relationship between $\partial P / \partial t$ and SST is much more chaotic than in observations. How $k_{2}$ and $k_{3}$ affect the forecast MISO is summarized in Fig. 12b. Immediately after the initiation, the postive $Q_{\text {net }}$ causes a SST warming ( $\left.\partial \mathrm{SST} / \partial t>0\right)$. However, because of a smaller $k_{2}$, the forecast SST anomaly is weaker. The weaker warm SST and the smaller $k_{3}$ jointly lead to slower transition of the MISO from the break to active phase [Eq. (4)], and as a result, the peak phase of the active spell is not only weaker but also delayed in time. This further involves weaker and delayed negative $Q_{\text {net }}$, which in turn leads to slower and delayed cooling of SST. With the model error growing over time, the forecast system slowly adjusts itself from the observational characteristics residing in the initial condition toward intrinsic characteristics of the model. The misrepresented air-sea coupling not only results in weakened MISO amplitude, but also leads to prolonged active and break phases, that is, a longer intrinsic period of the MISO (77 vs 47 days) than in observations, which manifests as slower propagation of MISOs and their delayed arrival in central India.

Therefore, $k_{2}$ and $k_{3}$ are the critical metrics for improving the air-sea interaction of CFSv2. The lower sensitivity of SST to $Q_{\text {net }}$ immediately points to the possibility of an overly large mean MLD in CFSv2. However, the MLD climatology in CFSv2 is actually shallower in the EAS-WBB region than Argo observations and cannot be responsible for the smaller $k_{2}$. We further propose that including a skin layer in the ocean component and better resolving the diurnal cycle may help to improve the SST $-Q_{\text {net }}$ relationship. The skin layer temperature has much stronger response to $Q_{\text {net }}$ forcing and thus enlarges $k_{2}$. Taking into account the diurnal cycle not only enhances intraseasonal SSTs $\left(k_{2}\right)$ but also improves the response of atmospheric deep convection to SST forcing $\left(k_{3}\right)$. The large daytime ocean warming during the active phase can induce an increase of $Q_{T}$ toward the atmosphere by up to $50 \mathrm{~W} \mathrm{~m}^{-2}$ (Fairall et al. 1996), which can significantly modify the atmospheric condition and influence the convection system (e.g., Webster et al. 1996; Woolnough et al. 2000; Bellenger et al. 2010). Our ongoing research is to use the atmospheric component of CFSv2 (i.e., GFS) to examine the impact of SST diurnal cycle on the modeled MISO rainfall.

The chaotic relationship between $\partial P / \partial t$ and SST in CFSv2 (Fig. 10f) reflects the major uncertainties of the model in representing the atmospheric convection and its associated moisture and cloud processes. Refining the parameterization of these processes will be helpful (e.g., Goswami et al. 2015; Abhik et al. 2017). Recent studies have revealed a sensitivity of MISOs to the ocean-atmosphere background state, such as the mean atmospheric circulation, SST, MLD, and barrier-layer thickness (e.g., Waliser et al. 2004; Roxy et al. 2013; Li et al. 2015, 2016, 2017b). The long-standing mean-state bias in CFSv2 (e.g., Figs. 4c,d) has definitely played a role in hindering the accurate MISO forecast. In addition, as a state-of-the-art reanalysis product, CFSR still shows some discrepancies from observations (e.g., Figs. 2 and 5) and particularly the SST anomalies, owing to the strong nudging towards in situ data, that are evidently weaker than satellite-measured skinlayer SST anomalies. Finally, we examined only $Q_{\text {net }}$ forcing effect on SST, but ocean processes, such as wave dynamics, mixing, advection, and barrier layer, can also exert a significant effect on intraseasonal SSTs for some events (Duncan and Han 2009; Li et al. 2014, 2016, 2017a,b). Model biases in representing these complicated oceanic processes may also induce forecast errors in the SST response to MISOs $\left(k_{2}\right)$. Regarding these facts, improvements in atmospheric convection parameterization, mean-state simulation, initial conditions, and ocean dynamics and mixing parameterization schemes will all add value to the more skillful prediction of the MISO.

Our results for the active and break conditions are basically "mirror images" to each other, with similar spatial-temporal patterns but opposite signs, and the misrepresented air-sea interaction in CFSv2 contribute to the forecast errors of both conditions. Yet detailed discrepancies are seen between them. Particularly, prediction skill for the active spell is significantly lower than that for the break spell. This arises from the fact that the active spell is more chaotic by its nature and is more difficult to predict (e.g., Abhilash et al. 2014; Goswami et al. 2014). This asymmetry reflects the nonlinearity of the MISO dynamics. It is still unknown whether it is rooted in the air-sea interaction or atmospheric internal processes of the active spell, or both.

Our analysis stressed the importance of air-sea interaction in the MISO forecast and examined the overall performance of CFSv2 in representing the 55 MISO events occurred in JJAS. The MISO air-sea interaction also shows prominent spatial, temporal, and event-byevent variability, caused by the effects of background conditions and synoptic disturbances. The precipitationSST relationship is different in the EAS, Bay of Bengal, and South China Sea regions (Roxy and Tanimoto 2007; Roxy et al. 2013; Li et al. 2016), and the sensitivities of the ocean and atmosphere to each other also vary with the seasonal cycle (e.g., Waliser et al. 2004; Li et al. 2016, 
2017b). The air-sea coupling in the EAS and the bay is particularly strong in May and June as a result of high mean SST, shallow mean MLD, and thin barrier layer (Li et al. 2016, 2017b). In addition, as local air-sea interaction in the north Indian Ocean and propagation from the equator are the two key components of the MISO dynamics, assessing their relative roles in the MISO predictability is of interest. Here we only examine the northward-propagating 30-60-day mode from the equator, and the northwestward-propagating 10-20-day mode from the western Pacific is not discussed, which also modulates the active-break spells (e.g., Kiladis and Weickmann 1997; Chatterjee and Goswami 2004). The findings of this paper may or may not hold true for the 10-20-day mode, which is worthy of further investigation and could be another error source for ISM prediction. Although the relationship between $Q_{\text {net }}$ and $P$ is realistic in CFSv2, the relationship between $Q_{\text {net }}$ components still shows detailed errors. The observed phase lag between SWR and $Q_{T}$ is missing in CFSv2 (Fig. 9), and the cold SST bias in the north Indian Ocean (Fig. 4) could be due to weaker prescribed $Q_{\text {net }}$. CFSv2 uses the Coupled Ocean-Atmosphere Response Experiment (COARE) bulk formulas in estimating air-sea turbulent fluxes. It is necessary to evaluate how well the COARE formulas work in the ISM region and to see whether the representation of $Q_{\text {net }}$ can be further improved. These ideas may be useful for the future expansion of the present study.

Acknowledgments. Two anonymous reviewers provided insightful comments for improving the manuscript. The authors gratefully acknowledge the financial support given by the Earth System Science Organization, Ministry of Earth Sciences, government of India (Grant SSC-03-002; Project No. MM/SERP/CNRS/ 2013/INT-10/002) to conduct this research under Monsoon Mission. Y. Li is also supported by National Natural Science Foundation of China (NSFC) Grant 41776001. W. Han and L. Zhang are also supported by NSF Grant OCE-1658132. CFSv2 45-day reforecast results and CFSR data are provided by NOMADS (online at http://nomads.ncdc.noaa.gov/) and NCAR (online at http://rda.ucar.edu/pub/cfsr.html); TMI SST product was downloaded from the TMI website (http://www.remss.com/missions/tmi); precipitation data from GPCP version 1.2 are available on the NOAA website (https:/data.noaa.gov/dataset/dataset/global-precipitationclimatology-project-gpcp-daily-version-1-2-versionsuperseded); and the Argo float data profiles are provided by the Coriolis Global Data Acquisition Center of France (available online at http://www. coriolis.eu.org/Data-Products/Catalogue\#/metadata/ 3df904de-e47d-4bf9-85a0-7c0942aff8b6). Most of the data processing and graphing were completed using a licensed Matlab R2017a program.

\section{REFERENCES}

Abhik, S., P. Mukhopadhyay, R. P. M. Krishna, K. D. Salunke, A. R. Dhakate, and S. A. Rao, 2016: Diagnosis of boreal summer intraseasonal oscillation in high resolution NCEP climate forecast system. Climate Dyn., 46, 3287-3303, https:// doi.org/10.1007/s00382-015-2769-9.

, R. P. M. Krishna, M. Mahakur, M. Ganai, P. Mukhopadhyay, and J. Dudhia, 2017: Revised cloud processes to improve the mean and intraseasonal variability of Indian summer monsoon in climate forecast system: Part 1.J. Adv. Model. Earth Syst., 9, 1002-1029, https://doi.org/10.1002/2016MS000819.

Abhilash, S., and Coauthors, 2014: Prediction and monitoring of monsoon intraseasonal oscillations over Indian monsoon region in an ensemble prediction system using CFSv2. Climate Dyn., 42, 2801-2815, https://doi.org/10.1007/s00382-0132045-9.

Bellenger, H., Y. N. Takayabu, T. Ushiyama, and K. Yoneyama, 2010: Role of diurnal warm layers in the diurnal cycle of convection over the tropical Indian Ocean during MISMO. Mon. Wea. Rev., 138, 2426-2433, https://doi.org/10.1175/ 2010MWR3249.1.

Bernie, D. J., E. Guilyardi, G. Madec, J. M. Slingo, and S. J. Woolnough, 2007: Impact of resolving the diurnal cycle in an ocean-atmosphere GCM. Part 1: A diurnally forced OGCM. Climate Dyn., 29, 575-590, https://doi.org/10.1007/ s00382-007-0249-6.

Bombardi, R. J., and Coauthors, 2015: Improvements in the representation of the Indian summer monsoon in the NCEP climate forecast system version 2. Climate Dyn., 45, 2485-2498, https://doi.org/10.1007/s00382-015-2484-6.

Chatterjee, P., and B. N. Goswami, 2004: Structure, genesis and scale selection of the tropical quasi-biweekly mode. Quart. J. Roy. Meteor. Soc., 130, 1171-1194, https://doi.org/10.1256/ qj.03.133.

Duncan, B., and W. Han, 2009: Indian Ocean intraseasonal sea surface temperature variability during boreal summer: Madden-Julian Oscillation versus submonthly forcing and processes. J. Geophys. Res., 114, C05002, https://doi.org/ 10.1029/2008JC004958.

Duvel, J. P., and J. Vialard, 2007: Indo-Pacific sea surface temperature perturbations associated with intraseasonal oscillations of tropical convection. J. Climate, 20, 3056-3082, https:// doi.org/10.1175/JCLI4144.1.

Fairall, C. W., E. F. Bradley, J. S. Godfrey, G. A. Wick, J. B. Edson, and G. S. Young, 1996: Cool-skin and warm-layer effects on sea surface temperature. J. Geophys. Res., 101, 1295-1308, https://doi.org/10.1029/95JC03190.

Fu, X., and B. Wang, 2004: Differences of boreal summer intraseasonal oscillations simulated in an atmosphere-ocean coupled model and an atmosphere-only model. J. Climate, 17, 1263-1271, https://doi.org/10.1175/1520-0442(2004)017<1263: DOBSIO $>2.0 . \mathrm{CO} ; 2$.

, - — and T. Li, 2002: Impacts of air-sea coupling on the simulation of mean Asian summer monsoon in the ECHAM4 Model. Mon. Wea. Rev., 130, 2889-2904, https://doi.org/ 10.1175/1520-0493(2002)130<2889:IOASCO >2.0.CO;2.

- — - — , and J. P. McCreary, 2003: Coupling between northward-propagating, intraseasonal oscillations and sea 
surface temperature in the Indian Ocean. J. Atmos. Sci., 60, 1733-1753, https://doi.org/10.1175/1520-0469(2003)060<1733: CBNIOA $>2.0 . \mathrm{CO} ; 2$.

,,-- D. E. Waliser, and L. Tao, 2007: Impact of atmosphereocean coupling on the predictability of monsoon intraseasonal oscillations. J. Atmos. Sci., 64, 157-174, https://doi.org/ 10.1175/JAS3830.1.

_- B. Yang, Q. Bao, and B. Wang, 2008: Sea surface temperature feedback extends the predictability of tropical intraseasonal oscillation. Mon. Wea. Rev., 136, 577-597, https://doi.org/ 10.1175/2007MWR2172.1.

_- B. Wang, J.-Y. Lee, W. Wang, and L. Gao, 2011: Sensitivity of dynamical intraseasonal prediction skills to different initial conditions. Mon. Wea. Rev., 139, 2572-2592, https://doi.org/ 10.1175/2011MWR3584.1.

Gadgil, S., and K. Rupa Kumar, 2006: The Asian monsoonAgriculture and economy. The Asian Monsoon, B. Wang, Ed., Springer, 651-683.

Ge, X., W. Wang, A. Kumar, and Y. Zhang, 2017: Importance of the vertical resolution in simulating SST diurnal and intraseasonal variability in an oceanic general circulation model. J. Climate, 30, 3963-3978, https://doi.org/10.1175/JCLI-D-160689.1.

Goswami, B. B., M. Deshpande, P. Mukhopadhyay, S. K. Saha, S. A. Rao, R. Murthugudde, and B. N. Goswami, 2014: Simulation of monsoon intraseasonal variability in NCEP CFSv2 and its role on systematic bias. Climate Dyn., 43, 2725-2745, https://doi.org/10.1007/s00382-014-2089-5.

- R. P. M. Krishna, P. Mukhopadhyay, M. Khairoutdinov, and B. N. Goswami, 2015: Simulation of the Indian summer monsoon in the superparameterized Climate Forecast System version 2: Preliminary results. J. Climate, 28, 8988-9012, https://doi.org/10.1175/JCLI-D-14-00607.1.

Goswami, B. N., and R. S. Ajaya Mohan, 2001: Intraseasonal oscillations and interannual variability of the Indian summer monsoon. J. Climate, 14, 1180-1198, https://doi.org/10.1175/ 1520-0442(2001)014<1180:IOAIVO>2.0.CO;2.

Griffies, S. M., M. J. Harrison, R. C. Pacanowski, and A. Rosati, 2003: A technical guide to MOM4. GFDL Ocean Group Tech. Rep. 5, 281 pp., http://data1.gfdl.noaa.gov/ arl/pubrel/j/ mom4beta/src/mom4/doc/guide.pdf.

Huffman, G. J., R. F. Adler, M. M. Morrissey, D. T. Bolvin, S. Curtis, R. Joyce, B. McGavock, and J. Susskind, 2001: Global precipitation at one-degree daily resolution from multi-satellite observations. J. Hydrometeor., 2, 36-50, https://doi.org/10.1175/ 1525-7541(2001)002<0036:GPAODD>2.0.CO;2.

Jiang, X., T. Li, and B. Wang, 2004: Structures and mechanisms of the northward propagating boreal summer intraseasonal oscillation. J. Climate, 17, 1022-1039, https://doi.org/10.1175/ 1520-0442(2004)017<1022:SAMOTN>2.0.CO;2.

—, S. Yang, Y. Li, A. Kumar, X. Liu, Z. Zuo, and B. Jha, 2013: Seasonal-to-interannual prediction of the Asian summer monsoon in the NCEP climate forecast system version 2 . J. Climate, 26, 3708-3727, https://doi.org/10.1175/JCLI-D-1200437.1.

Joseph, P. V., and T. P. Sabin, 2008: An ocean-atmosphere interaction mechanism for the active break cycle of the Asian summer monsoon. Climate Dyn., 30, 553-566, https://doi.org/ 10.1007/s00382-007-0305-2.

Kemball-Cook, S., and B. Wang, 2001: Equatorial waves and airsea interaction in the boreal summer intraseasonal oscillation. J. Climate, 14, 2923-2942, https://doi.org/10.1175/1520-0442 (2001) $014<2923$ :EWAASI $>2.0$. CO;2.
Kiladis, G. N., and K. M. Weickmann, 1997: Horizontal structure and seasonality of large-scale circulations associated with submonthly tropical convection. Mon. Wea. Rev., 125, 1997-2013, https://doi.org/10.1175/1520-0493(1997)125<1997: HSASOL $>2.0 . \mathrm{CO} ; 2$.

Kim, H.-M., P. J. Webster, J. A. Curry, and V. E. Toma, 2012: Asian summer monsoon prediction in ECMWF system 4 and NCEP CFSv2 retrospective seasonal forecasts. Climate Dyn., 39, 2975-2991, https://doi.org/10.1007/s00382-012-1470-5.

Lawrence, D. M., and P. J. Webster, 2002: The boreal summer intraseasonal oscillation: Relationship between northward and eastward movement of convection. J. Atmos. Sci., 59, 1593-1606, https://doi.org/10.1175/1520-0469(2002)059<1593: TBSIOR $>2.0 . \mathrm{CO} ; 2$.

Li, Y., W. Han, T. Shinoda, C. Wang, R.-C. Lien, J. N. Moum, and J.-W. Wang, 2013: Effects of the diurnal cycle in solar radiation on the tropical Indian Ocean mixed layer variability during wintertime Madden-Julian oscillations. J. Geophys. Res. Oceans, 118, 4945-4964, https://doi.org/10.1002/ jgrc. 20395 .

,,,---- M. Ravichandran, and J.-W. Wang, 2014: Revisiting the wintertime intraseasonal SST variability in the tropical South Indian Ocean: Impact of the ocean interannual variation. J. Phys. Oceanogr., 44, 1886-1907, https://doi.org/ 10.1175/JPO-D-13-0238.1.

$\longrightarrow, \ldots$, and T. Lee, 2015: Intraseasonal sea surface salinity variability in the equatorial Indo-Pacific Ocean induced by Madden-Julian oscillations. J. Geophys. Res. Oceans, 120, 2233-2258, https://doi.org/10.1002/2014JC010647.

_ - - W. Wang, and M. Ravichandran, 2016: Intraseasonal variability of SST and precipitation in the Arabian Sea during Indian summer monsoon: Impact of the ocean mixed layer depth. J. Climate, 29, 7889-7910, https://doi.org/10.1175/JCLID-16-0238.1.

- - - M. Ravichandran, W. Wang, T. Shinoda, and T. Lee, 2017a: Bay of Bengal salinity stratification and Indian summer monsoon intraseasonal oscillation: 1 . Intraseasonal variability and causes. J. Geophys. Res. Oceans, 122, 4291-4311, https:// doi.org/10.1002/2017JC012691.

- - - W. Wang, M. Ravichandran, T. Lee, and T. Shinoda, 2017b: Bay of Bengal salinity stratification and Indian summer monsoon intraseasonal oscillation: 2. Impact on SST and convection. J. Geophys. Res. Oceans, 122, 4312-4328, https:// doi.org/10.1002/2017JC012692.

Lin, J.-L., K. M. Weickman, G. N. Kiladis, B. E. Mapes, S. D. Schubert, M. J. Suarez, J. T. Bacmeister, and M.-I. Lee, 2008: Subseasonal variability associated with Asian summer monsoon simulated by 14 IPCC AR4 coupled GCMs. J. Climate, 21, 4541-4567, https:// doi.org/10.1175/2008JCLI1816.1.

Lindzen, R. S., and S. Nigam, 1987: On the role of sea surface temperature gradients in forcing low-level winds and convergence in the tropics. J. Atmos. Sci., 44, 2418-2436, https://doi.org/ 10.1175/1520-0469(1987)044<2418:OTROSS > 2.0.CO;2.

Madden, R. A., and P. R. Julian, 1971: Detection of a 40-50 day oscillation in the zonal wind in the tropical Pacific. J. Atmos. Sci., 28, 702-708, https://doi.org/10.1175/1520-0469(1971) 028<0702:DOADOI $>2.0$. CO;2.

Mujumdar, M., K. Salunke, S. A. Rao, M. Ravichandran, and B. N. Goswami, 2011: Diurnal cycle induced amplification of sea surface temperature intraseasonal oscillations over the Bay of Bengal in summer monsoon season. IEEE Geosci. Remote Sens. Lett., 8, 206-210, https://doi.org/10.1109/ LGRS.2010.2060183. 
Narapusetty, B., R. Murtugudde, H. Wang, and A. Kumar, 2016: Ocean-atmosphere processes driving Indian summer monsoon biases in CFSv2 hindcasts. Climate Dyn., 47, 1417-1433, https://doi.org/10.1007/s00382-015-2910-9.

Rai, S., and V. Krishnamurthy, 2011: Error growth in Climate Forecast System daily retrospective forecasts of South Asian monsoon. J. Geophys. Res., 116, D03108, https://doi.org/ 10.1029/2010JD014840.

Rajeevan, M., S. Gadgil, and J. Bhate, 2010: Active and break spells of the Indian summer monsoon. J. Earth Syst. Sci., 119, 229247, https://doi.org/10.1007/s12040-010-0019-4.

Ramu, D. A., and Coauthors, 2016: Indian summer monsoon rainfall simulation and prediction skill in the CFSv2 coupled model: Impact of atmospheric horizontal resolution. J. Geophys. Res. Atmos., 121, 2205-2221, https://doi.org/ 10.1002/2015JD024629.

Reynolds, R. W., T. M. Smith, C. Liu, D. B. Chelton, K. S. Casey, and M. G. Schlax, 2007: Daily high-resolution-blended analyses for sea surface temperature. J. Climate, 20, 5473-5496, https://doi.org/10.1175/2007JCLI1824.1.

Roxy, M., 2014: Sensitivity of precipitation to sea surface temperature over the tropical summer monsoon region-And its quantification. Climate Dyn., 43, 1159-1169, https://doi.org/ 10.1007/s00382-013-1881-y.

, and Y. Tanimoto, 2007: Role of SST over the Indian Ocean in influencing the intraseasonal variability of the Indian summer monsoon. J. Meteor. Soc. Japan, 85, 349-358, https://doi.org/ 10.2151/jmsj.85.349.

— and - 2012: Influence of sea surface temperature on the intraseasonal variability of the South China Sea summer monsoon. Climate Dyn., 39, 1209-1218, https://doi.org/ 10.1007/s00382-011-1118-x.

,,-- B. Preethi, P. Terray, and R. Krishnan, 2013: Intraseasonal SST-precipitation relationship and its spatial variability over the tropical summer monsoon region. Climate Dyn., 41, 4561, https://doi.org/10.1007/s00382-012-1547-1.

Sabeerali, C. T., A. Ramu Dandi, A. Dhakate, K. Salunke, S. Mahapatra, and S. A. Rao, 2013: Simulation of boreal summer intraseasonal oscillations in the latest CMIP5 coupled GCMs. J. Geophys. Res. Atmos., 118, 4401-4420, https://doi.org/ $10.1002 /$ jgrd. 50403 .

Saha, S., and Coauthors, 2010: The NCEP Climate Forecast System Reanalysis. Bull. Amer. Meteor. Soc., 91, 1015-1057, https:// doi.org/10.1175/2010BAMS3001.1.

_- and Coauthors, 2014: The NCEP Climate Forecast System version 2. J. Climate, 27, 2185-2208, https://doi.org/10.1175/ JCLI-D-12-00823.1.

Saha, S. K., and Coauthors, 2014: Improved simulation of Indian summer monsoon in latest NCEP climate forecast system free run. Int. J. Climatol., 34, 1628-1641, https://doi.org/10.1002/joc.3791.

Sahai, A. K., S. Abhilash, R. Chattopadhyay, N. Borah, S. Joseph, S. Sharmila, and M. Rajeevan, 2015: High-resolution operational monsoon forecasts: An objective assessment. Climate Dyn., 44, 3129-3140, https://doi.org/10.1007/s00382-014-2210-9.

Sengupta, D., B. N. Goswami, and R. Senan, 2001: Coherent intraseasonal oscillations of ocean and atmosphere during the Asian summer monsoon. Geophys. Res. Lett., 28, 4127-4130, https://doi.org/10.1029/2001GL013587.

Seo, K.-H., J.-K. E. Schemm, W. Wang, and A. Kumar, 2007: The boreal summer intraseasonal oscillation simulated in the NCEP Climate Forecast System: The effect of sea surface temperature. Mon. Wea. Rev., 135, 1807-1827, https://doi.org/ 10.1175/MWR3369.1.
Sharmila, S., and Coauthors, 2013: Role of ocean-atmosphere interaction on northward propagation of Indian summer monsoon intra-seasonal oscillations (MISO). Climate Dyn., 41, 1651-1669, https://doi.org/10.1007/s00382-013-1854-1.

Shenoi, S. S. C., N. Nasnodkar, G. Rajesh, K. Jossia Joseph, I. Suresh, and A. M. Almeida, 2009: On the diurnal ranges of sea surface temperature (SST) in the north Indian Ocean. J. Earth Syst. Sci., 118, 483-496, https://doi.org/10.1007/ s12040-009-0038-1.

Shinoda, T., 2005: Impact of the diurnal cycle of solar radiation on intraseasonal SST variability in the western equatorial Pacific. J. Climate, 18, 2628-2636, https://doi.org/10.1175/ JCLI3432.1.

- H. H. Hendon, and J. Glick, 1998: Intraseasonal variability of surface fluxes and sea surface temperature in the tropical western Pacific and Indian Oceans. J. Climate, 11, 16851702, https://doi.org/10.1175/1520-0442(1998)011<1685: IVOSFA $>2.0 . \mathrm{CO} ; 2$.

Sikka, D. R., and S. Gadgil, 1980: On the maximum cloud zone and the ITCZ over Indian, longitudes during the southwest monsoon. Mon. Wea. Rev., 108, 1840-1853, https://doi.org/10.1175/ 1520-0493(1980)108<1840:OTMCZA > 2.0.CO;2.

Sperber, K. R., H. Annamalai, I.-S. Kang, A. Kitoh, A. Moise, A. Turner, B. Wang, and T. Zhou, 2013: The Asian summer monsoon: An intercomparison of CMIP5 vs. CMIP3 simulations of the late 20th century. Climate Dyn., 41, 2711-2744, https://doi.org/10.1007/s00382-012-1607-6.

Vecchi, G. A., and D. E. Harrison, 2002: Monsoon breaks and subseasonal sea surface temperature variability in the Bay of Bengal. J. Climate, 15, 1485-1493, https://doi.org/10.1175/ 1520-0442(2002)015<1485:MBASSS > 2.0.CO;2.

Vialard, J., A. Jayakumar, C. Gnanaseelan, M. Lengaigne, D. Sengupta, and B. Goswami, 2012: Processes of 30-90 days sea surface temperature variability in the northern Indian Ocean during boreal summer. Climate Dyn., 38, 1901-1916, https://doi.org/ 10.1007/s00382-011-1015-3.

Waliser, D. E., Z. Zhang, K. M. Lau, and J.-H. Kim, 2001: Interannual sea surface temperature variability and the predictability of tropical intraseasonal variability. J. Atmos. Sci., 58, 2596-2615, https://doi.org/10.1175/1520-0469(2001)058<2596: ISSTVA $>2.0 . \mathrm{CO} ; 2$.

, R. Murtugudde, and L. E. Lucas, 2004: Indo-Pacific Ocean response to atmospheric intraseasonal variability: 2 . Boreal summer and the intraseasonal oscillation. J. Geophys. Res., 109, C03030, https://doi.org/10.1029/2003JC002002.

Wang, B., and X. Xie, 1997: A model for the boreal summer intraseasonal oscillation. J. Atmos. Sci., 54, 72-86, https://doi.org/ 10.1175/1520-0469(1997)054<0072:AMFTBS > 2.0.CO;2.

—, Q. Ding, X. Fu, I.-S. Kang, K. Jin, J. Shukla, and F. DoblasReyes, 2005: Fundamental challenge in simulation and prediction of summer monsoon rainfall. Geophys. Res. Lett., 32, L15711, https://doi.org/10.1029/2005GL022734.

Wang, J., W. Wang, X. Fu, and K.-H. Seo, 2012: Tropical intraseasonal rainfall variability in the CFSR. Climate Dyn., 38, 2191-2207, https://doi.org/10.1007/s00382-011-1087-0.

Wang, W., M. Chen, and A. Kumar, 2009: Impacts of ocean surface on the northward propagation of the boreal summer intraseasonal oscillation in the NCEP Climate Forecast System. J. Climate, 22, 6561-6576, https://doi.org/10.1175/2009JCLI3007.1.

, P. Xie, S.-H. Yoo, Y. Xue, A. Kumar, and X. Wu, 2011: An assessment of the surface climate in the NCEP Climate Forecast System Reanalysis. Climate Dyn., 37, 1601-1620, https://doi.org/10.1007/s00382-010-0935-7. 
—_, M.-P. Hung, S. J. Weaver, A. Kumar, and X. Fu, 2014: MJO prediction in the NCEP Climate Forecast System version 2. Climate Dyn., 42, 2509-2520, https://doi.org/10.1007/ s00382-013-1806-9.

Webster, P. J., C. A. Clayson, and J. A. Curry, 1996: Clouds, radiation, and the diurnal cycle of sea surface temperature in the tropical western Pacific. J. Climate, 9, 17121730, https://doi.org/10.1175/1520-0442(1996)009<1712: CRATDC $>2.0 . \mathrm{CO} ; 2$.

, V. O. Magaña, T. N. Palmer, J. Shukla, R. A. Tomas, M. Yanai, and T. Yasunari, 1998: Monsoons: Processes, predictability, and the prospects for prediction. J. Geophys. Res., 103, 14 451-14 510, https://doi.org/10.1029/97JC02719.

, and Coauthors, 2002: The JASMINE pilot study. Bull. Amer. Meteor. Soc., 83, 1603-1630, https://doi.org/10.1175/ BAMS-83-11-1603.
Wentz, F. J., C. Gentemann, D. Smith, and D. Chelton, 2000: Satellite measurements of sea surface temperature through clouds. Science, 288, 847-850, https://doi.org/10.1126/ science.288.5467.847.

Woolnough, S. J., J. M. Slingo, and B. J. Hoskins, 2000: The relationship between convection and sea surface temperature on intraseasonal timescales. J. Climate, 13, 2086-2104, https:// doi.org/10.1175/1520-0442(2000)013<2086:TRBCAS > 2.0.CO;2.

Xue, Y., B. Huang, Z.-Z. Hu, A. Kumar, C. Wen, D. Behringer, and S. Nadiga, 2011: An assessment of oceanic variability in the NCEP climate forecast system reanalysis. Climate Dyn., 37, 2511-2539, https://doi.org/10.1007/s00382-010-0954-4.

Yasunari, T., 1980: A quasi-stationary appearance of 30 to 40 day period in the cloudiness fluctuations during the summer monsoon over India. J. Meteor. Soc. Japan, 58, 225-229, https://doi.org/10.2151/jmsj1965.58.3_225. 